\title{
Quality control of HLA-DR molecules by the lysosomal aspartyl protease, cathepsin D
}

Nakul Shah ${ }^{1}$, Sarah McDonald*2 ${ }^{2}$, Charles T.A. Parker*2, Ryan W.M. Robinson*2 ${ }^{* 2}$ Amin Oomatia*2, Alessandra De Riva*2 $^{*}$, Michael J. Deery ${ }^{3}$, Elizabeth D. Mellins ${ }^{4}$, Robert Busch $^{1,2 \#}$

${ }^{1}$ Dept of Life Sciences, University of Roehampton, London, UK

${ }^{2}$ Dept of Medicine, University of Cambridge, Cambridge, UK

${ }^{3}$ Cambridge Centre for Proteomics, Cambridge, UK

${ }^{4}$ Dept of Pediatrics, Program in Immunology, Stanford University, Stanford, CA, USA

* SMcD, CTAP, RWMR, AO, ADR and MJD all made similar contributions.

\# Corresponding author: robert.busch@roehampton.ac.uk.

Running title: CatD degrades empty HLA-DR

Key words: Major histocompatibility complex class II, human leukocyte antigen DR, lysosomal proteolysis, aspartyl cathepsins, protein turnover, quality control, peptide binding, mass spectrometry, flow cytometry, Western blot. 


\section{Abstract (221 words)}

Major histocompatibility complex class II (MHCII $)^{1}$ molecules display peptides on antigen-presenting cells (APCs) for inspection by CD4+ T cells. MHCII surface levels and life span are regulated post-translationally by peptide loading and ubiquitindependent lysosomal targeting, but proteases responsible for MHCII protein degradation remain unidentified. Here, we examined the role of aspartyl proteases in MHCII protein degradation and characterised the form of MHCII that is degraded. Exposure of immature monocyte-derived dendritic cells (MoDCs) and KG-1 acute myeloid leukaemia cells to the aspartyl protease inhibitor, pepstatin A (PepA), caused accumulation of human leukocyte antigen (HLA)-DR molecules in intracellular vesicles. Statistically significant PepA effects on MHCII protein expression were also observed in murine APCs. In KG-1 cells, cathepsin D (CatD) was the sole expressed aspartyl protease, and shRNA-mediated knockdown ablated the PepA effect, providing formal proof of CatD involvement. In vitro, CatD initiated specific cleavage of recombinant DR at $\alpha \mathrm{F} 54$, a site flanking the peptide-binding groove. Immunochemical characteristics of PepA-rescued DR molecules in KG-1 cells were consistent with selective CatD attack on HLA-DR molecules that lack association with the MHCII chaperone, invariant chain, or with stably bound peptide. We propose that CatD has a critical role in the selective lysosomal disposal of mature HLADR molecules that have lost, or never acquired, bound peptide, explaining how MHCII protein life span is coupled to peptide loading. 


\section{Introduction}

Major histocompatibility complex class II (MHCII) glycoproteins present diverse self and foreign peptides to drive immune tolerance and adaptive immunity, respectively, after detection by antigen receptors of CD4+ T lymphocytes (1). Under the control of the class II transactivator (CIITA), MHCII molecules are expressed constitutively on myeloid antigen-presenting cells (APCs), B lymphocytes and thymic epithelial cells and induced on other cell types by proinflammatory cytokines (2,3). Peptide loading of MHC class II molecules is largely confined to endosomes, due to regulation of intracellular transport and occupancy of the peptide-binding groove by invariant chain, a chaperone that binds MHCII molecules in the endoplasmic reticulum (4-6). Nascent MHCII $\alpha \beta$ dimers, after assembling with Ii, are transported to late endosomes/early lysosomes, where proteases successively trim Ii, leaving class II-associated Ii peptides (CLIP) in the peptide-binding groove. CLIP is then exchanged for endosomal peptides, either spontaneously or through catalysis by HLA-DM, a non-classical MHCII homolog that stabilises empty MHCII molecules, protects them from degradation, and edits in favour of kinetically stable peptide/MHCII complexes. These complexes are expressed at the plasma membrane and, after a time, the MHCII molecules may be re-internalised into lysosomes and degraded. One unresolved question is how MHCII molecules can survive in the proteolytic environment of endocytic compartments while being loaded with peptides, only to be degraded later when needed. 
MHCII protein turnover rates are affected by the cellular milieu, with half-lives ranging from hours to weeks (7). In vivo, MHCII degradation rates are slower in murine B cells than dendritic cells (DCs) (8). In human and murine DCs differentiated in vitro, MHCII degradation is shut down by proinflammatory cytokines and pathogen-derived molecular patterns $(9,10)$ : in non-activated DCs, ubiquitylation of the MHCII $\beta$-chain cytoplasmic tail (catalysed by the E3 ligase, MARCH-1) promotes internalization and enables lysosomal degradation, whereas MARCH-1 expression ceases when DCs are activated (11-14). This mechanism may allow the persistent presentation of antigen by DCs during CD4+ T-cell activation and exhaustion $(15,16)$. In follicular B cells and macrophages, downregulation of constitutively expressed MARCH-1 is involved in the induction of MHCII by interleukin-10 $(17,18)$, whereas at the centroblast stage of B-cell differentiation in the germinal center, induction of MARCH-1 and MHCII internalization limits antigen presentation during the selection of mutated BCRs for high antigen affinity (19).

Another factor regulating the turnover of MHCII proteins is their peptide loading state. Peptide dissociation half-lives limit the persistence of peptide/MHCII protein complexes on APC surfaces (20). Acquisition of a stable peptide repertoire can be impaired in cells that lack the peptide editor, DM, and/or due to un-edited peptide loading following spontaneous CLIP release from MHCII allelic variants with low CLIP affinity; in such settings, MHCII protein turnover is accelerated (21-25). Biophysical studies show that tightly-bound peptides stabilise MHCII molecules (26,27), yet the molecular mechanisms 
linking poor peptide loading to lysosomal MHCII protein turnover in vivo remain undefined.

Little is known about the proteases that mediate physiological MHCII turnover. Early biochemical studies highlighted the resistance of tightly folded MHCII ectodomains to proteases in vitro $(28,29)$, but the enzymes used in these studies are not available during lysosomal protein turnover in vivo. Inhibition of lysosomal cysteine proteases rescued only a small proportion of the MHCII protein, human leukocyte antigen (HLA)-DR, on the surface of human immature monocyte-derived dendritic cells (MoDCs)(30); moreover, in vitro digestion of purified DR with several cysteine proteases failed to produce detectable cleavage (31). The serine protease, cathepsin (Cat) G, cleaved HLADR $\beta$-chains in vitro, but a specific CatG inhibitor had no effect in vivo, so the relevance to physiological degradation is doubtful (31). Genetic screens for factors influencing MHCII protein expression failed to identify any lysosomal proteases (32). Similarly, targeted knockouts of various cathepsins in mice provided no evidence of specific involvement in the turnover of MHCII $\alpha \beta$ dimers, despite clear evidence that several cathepsins are involved in processing Ii (33) or in the generative or destructive processing of antigenic peptides $(34,35)$.

Here, we examined the roles of two aspartyl proteases found in APCs, cathepsin D and cathepsin $\mathrm{E}(\mathrm{CatD} / \mathrm{E})$ in MHCII protein turnover. These enzymes use active-site aspartyl residues to mediate proteolytic attack on peptide bonds and can be blocked with a specific inhibitor, pepstatin A (PepA)(36). CatD localises to late endosomal/lysosomal 
compartments, whereas CatE has been found in a distinct set of endosomes of APCs; both have been implicated in antigen processing using inhibitors and knockout mice (34,37-42). Even though none of these studies reported any effects on MHCII expression levels, they did not rule out a role of CatD and/or CatE in MHCII protein turnover. To address this possibility, we here examined the accumulation of MHCII molecules following PepA treatment of various APC types; in addition, in a myeloid model APC line, we identified CatD as the enzyme responsible for the PepA effect and explored which forms of HLA-DR class II molecules are subject to proteolytic attack. 


\section{Results}

$\underline{\text { PepA-mediated rescue of MHCII molecules in cultured APCs }}$

To examine the role of aspartyl proteases in HLA-DR protein turnover, APCs were incubated with the aspartyl protease inhibitor, PepA $(20 \mu \mathrm{M})$ for up to three days. Total (surface plus intracellular) amounts of mature (Ii-non-associated, heterodimeric) DR molecules were quantified by direct immunofluorescent staining of fixed, permeabilized cells with the monomorphic anti-DR $\alpha$ mAb, L243 (see Methods), followed by flow cytometry (Fig. 1 and Supporting Information, Fig. S1, A-C). In the DR ${ }^{+}$myeloid leukemic cell line, KG-1, HLA-DR accumulated following PepA treatment (compared with vehicle control) with approximately linear kinetics at $\approx 25 \%$ per day over the first 48 hours of culture (Fig. 1A, B). The accumulation seen in Fig. 1B at 48 hours was reproducible (mean $48 \% \pm 28 \%$ increase compared to vehicle control) in multiple experiments (Fig. 1C). No accumulation was seen at the plasma membrane (Fig. 1D), implying that the rescued DR molecules were intracellular. Together, these findings implicated aspartyl proteases in HLA-DR protein turnover.

\section{Fig. 1 here}

Normal growth media may contain varying amounts of the lysosomotropic agent, ammonia, due to spontaneous hydrolysis of L-glutamine, resulting in a slow-down of lysosomal degradation $(43,44)$. To examine whether the PepA effect was observable in the absence of this potential confounding variable, KG-1 cells were switched to media containing GlutaMax, a non-hydrolyzable source of glutamine, and the experiment in Fig. 
1B repeated (Fig. S2A). Again, PepA caused HLA-DR accumulation, to a comparable extent (32\% maximal increase), but this time the effect peaked at 6-24 hours. Thus, the PepA effect was observed regardless of the source of glutamine and its effect on lysosomal activity, but the time of maximal PepA effect was affected by the source of glutamine, likely reflecting differences in lysosomal activity. Interestingly, DR accumulation levelled off after 48 hours in normal culture media (Fig. 1B) and subsequently diminished in GlutaMax media (Fig. S2A; cf. Discussion).

Because $20 \mu \mathrm{M}$ was the highest dose of PepA achievable without toxicity, we examined whether an analogue engineered for increased intracellular bioavailability, PepApenetratin, might achieve greater rescue of HLA-DR molecules. However, the rescue achieved with $10 \mu \mathrm{M}$ PepA-penetratin was not substantially greater than with $20 \mu \mathrm{M}$ unconjugated PepA (Fig. S2B).

As a specificity control, we previously reported that HLA class I molecules are not detectably rescued by PepA (or by any other protease inhibitors) in KG-1 cells (45). This suggests that CatD has no role in HLA class I degradation in this cell line, or that this enzyme acts redundantly with other lysosomal cathepsins on class I molecules.

In immature monocyte-derived dendritic cells (MoDCs, Fig. 1E and Fig. S3), PepA rescue of HLA-DR was similar in magnitude (mean $\approx 25 \%$ increased L243 staining after 24 hours) as in KG-1 cells at the same time point. We and others have shown previously that immature MoDCs exhibited HLA-DR turnover with half-lives of $\approx 1$ day $(9,45)^{2}$, so 
that the $25 \% / \mathrm{d}$ rate of DR accumulation due to PepA accounted for ca. half of the reported turnover rate. In the EBV-transformed B-lymphoblastoid cell line, Priess, a small amount of HLA-DR accumulation was observed in the presence of PepA in some experiments (Fig. 1F), but not others. This was consistent with the very slow HLA-DR protein turnover in Priess cells detected by ${ }^{2} \mathrm{H}_{2} \mathrm{O}$ labelling $\left(\mathrm{t}_{1 / 2}>60 \mathrm{~h}\right)^{3}$. Taken together, the data suggest that the PepA effects correlate with rates of HLA-DR protein turnover, where known.

The PepA effect was not confined to human APCs. We observed varying extents of rescue by PepA of several murine MHC class II proteins in splenic B cells and DCs (Fig. S4). Thus, the observed role of aspartyl proteases in HLA-DR protein turnover may extend to other MHCII molecules.

$\underline{\text { Role of CatD in the degradation of HLA-DR proteins in KG-1 cells }}$

Next, we sought to identify the aspartyl protease responsible for the effect of PepA on HLA-DR levels. The two lysosomal aspartyl proteases, CatD and CatE, share homology (46) but can be distinguished on Western blot by immunoreactivity and the fact that CatE, unlike CatD, exists as a disulfide-bonded homodimer (Fig. 2, A and B). KG-1 cells showed substantial expression of CatD, whereas Priess cells expressed much lower quantities of this enzyme, visible only on long exposure of blots, with a different processing pattern (Fig. 2A). This was consistent with the lack of PepA effect in Priess cells (cf. Fig. 1). Neither cell line expressed detectable CatE protein (Fig. 2B). Quantitative real-time RT-PCR confirmed the presence of messenger RNA for CatD, but not CatE (Fig. S5), and CatD expression in KG-1 cells was confirmed by flow cytometry 
(Fig. S1C). CatD and HLA-DR immunoreactivity are known to co-localize in late endosomal/lysosomal compartments $(47,48)$. Thus, CatD was the only expressed aspartyl protease that could plausibly account for the PepA effect.

Fig. 2 here

To test formally whether CatD was responsible for the PepA effect on DR expression, lentiviral shRNA knockdown of CatD was performed in KG-1 cells, yielding a 96\% reduction in $\mathrm{CatD}$ expression (Fig. 2C). KG-1 cells transduced with empty vector maintained the effect of PepA on HLA-DR expression (Fig. 2D), with similar kinetics as seen before (cf. Fig. 1B), but CatD knockdown resulted in almost complete ablation of the PepA effect. This provided genetic evidence that the PepA effect, and by implication the turnover of HLA-DR in the wild-type cells, was dependent on CatD expression. Interestingly, steady-state expression of DR in the CatD-depleted KG-1 cells was not elevated above wild-type (Fig. 2D; cf. Discussion).

\section{$\underline{\text { CatD performs HLA-DR cleavage at } \alpha \text { Phe54 in vitro }}$}

In order to examine whether CatD directly acts on HLA-DR ectodomains in vitro, we subjected purified recombinant soluble DR0402 to digestion by human CatD under mildly acidic (endosome-like) conditions and analysed cleavage products by SDS-PAGE and silver staining (Fig. 3). Little evidence of CatE cleavage was found, and CatD cleaved only a small proportion of offered DR molecules under these conditions (Fig. 3A, cf. Discussion). Nonetheless, three specific CatD cleavage fragments were detected by 
silver staining, which were not present in control reactions without enzyme, or when the enzyme was inhibited by PepA. The bands were excised and analysed by tandem mass spectrometry. The known cleavage preferences of CatD (after large hydrophobic residues) and trypsin (after Arg/Lys) are non-overlapping, so we compared tryptic digests of the fragments, looking for novel cleavage products in the CatD fragments that were absent from the intact DR bands (Fig. 3B; Table S1 and Fig. S6). By mass spectrometric analysis, the largest CatD fragment (D1, $18 \mathrm{kDa})$ showed evidence of $\alpha$-chain cleavage at the Phe54-Glu55 peptide bond, which is compatible with the known preference of CatD for cleavage after Phe or Leu. Moreover, we scanned the DR $\alpha$ amino acid sequence against the known cleavage preferences of $\mathrm{CatD}$, considering the frequencies of all 20 amino acids at each of the four residues on either side of known CatD cleavage sites (cf. Experimental Procedures, Tables S2-S4 and supporting text). According to this analysis, $\alpha \mathrm{Phe} 54$ was the top-ranked cleavage site (Fig. 3C). Inspection of the HLA-DR crystal structure showed that $\alpha \mathrm{Phe} 54$ was in the extended strand C-terminal to the $\alpha$-chain helix, facing the bound peptide (Fig. 3D, shown in magenta)(26). This result is compatible with a model whereby CatD initiates direct attack on HLA-DR proteins, cleaving at $\alpha \mathrm{Phe} 54$ (see Discussion). The smaller bands (D2, $16 \mathrm{kDa}$ and D3, $14 \mathrm{kDa}$ ) contained $\alpha$-chain peptides consistent with one or more secondary CatD cleavages: residue $\alpha \mathrm{Phe} 51$ was close to $\alpha$ Phe54, whereas $\alpha$ Leu92was buried at the $\alpha_{2} / \beta_{2}$ domain interface, distant from the peptide-binding groove (Fig. 3D, shown in light green at right; Table S1). Although tryptic $\beta$-chain fragments were observed (Table S1 and Fig. S6A), they spanned most of the sequence, and of the few novel peptides observed, none matched the cleavage preferences of CatD (Fig. S6B). 


\section{Fig. 3 here}

\section{Characterisation of HLA-DR molecules rescued by PepA in KG-1 cells}

HLA-DR associates with different molecules during its intracellular maturation and fate (see Introduction), so we examined which forms of DR were rescued in KG-1 cells after 2 days of culture with PepA. First, noting that DR molecules loaded with stable peptides acquire resistance to SDS denaturation at room temperature (49-51), SDS stability was evaluated by Western blot (Fig. 4A). Antibodies to the DR $\alpha$ or $\beta$ chain were used, which had different preferences for SDS-unstable vs. SDS-stable forms of DR. Regardless of this, the band intensity of SDS-stable $\alpha \beta$ /peptide heterotrimers was unaffected by PepA, whereas the abundance of SDS-unstable molecules almost doubled in extracts from PepA-treated vs. control KG-1 cells (Fig. 4B, left). When the extracts were boiled, the SDS-stable bands disappeared and the intensity of the monomer bands increased, as expected (Fig. 4A); quantification showed an increase in PepA-treated cells comparable to that seen by flow cytometry (cf. Fig. 4B, right and Fig. 1B). Together, these findings implied that PepA did not rescue DR molecules that acquired stably bound peptide and focussed further analysis on other forms of DR that are not SDS-stable.

\section{Fig. 4 here}

Importantly, the DR molecules rescued by PepA were not detectably ubiquitinated, which would have produced a ladder above the main $\beta$-chain monomer band with an $8 \mathrm{kDa}$ 
spacing (Fig. 4A, right). Neither did any lower-molecular weight fragments accumulate in the presence of PepA, suggesting that intact molecules, rather than partial cleavage products generated by other enzymes, were rescued.

The mAb used to detect DR $\alpha \beta$ dimers in Fig. 1, L243, reacts poorly with Ii-associated DR (cf. Methods), suggesting that the L243-reactive DR molecules rescued by PepA were not Ii-associated. Nonetheless, we examined this possibility directly, because previous studies had provided evidence for $(52)$ and against $(40,53,54)$ aspartyl protease involvement in the initial processing of the class II-associated Ii; variation in this regard may be due to differences in lysosomal protease composition or HLA class II genotype (55). In KG-1 cells, however, PepA failed to mediate any detectable rescue of Ii or its fragments, as shown both by flow cytometric analysis with Ii-specific mAb (Fig. 4C and Fig. S1E; time course in media with glutamine or GlutaMax shown in Fig. S2A, bottom) or by Western blot analysis of full-length Ii and its degradation intermediates (Fig. 4D). Thus, the intracellular accumulation of DR in PepA-treated KG-1 cells was not due to arrest of Ii processing in the endocytic pathway. The terminal Ii processing product, DRassociated CLIP, was not detectable in the KG-1 cells by flow cytometry with CLIPspecific antibody (Fig. S1E); at least one of the two coexpressed DRB1 alleles in KG-1 cells, DRB1*11:01, has been reported to have only modest CLIP affinity (56).

Fig. 5A compares the biochemical characteristics of the PepA-rescued DR molecules with the known characteristics of the different maturation stages of DR. The findings are consistent with the rescue of empty or poorly-loaded DR molecules from degradation by 

available under aCC-BY-NC-ND 4.0 International license.

PepA; in contrast, neither ubiquitylated DR molecules, SDS-stable complexes containing stably-bound peptides, or DR molecules associated with Ii or Ii degradation intermediates, such as p20LIP, were rescued by PepA.

\section{Fig. 5 here}




\section{Discussion}

This study identified a novel role of the aspartyl protease, CatD, in the degradation of MHCII proteins. MHCII expression level and lifespan have been linked to peptide loading $(7,20,21)$ and are regulated in APCs by $\beta$-chain ubiquitylation and internalization $(11,12)$. Using the aspartyl protease inhibitor, PepA, expression analysis and shRNA knockdown, we showed in a well-characterised model APC line that CatD is involved in the degradation of HLA-DR molecules. By targeting a site on DR that is involved in "locking" peptides into the peptide-binding groove, CatD seems to target DR molecules that are not associated with Ii or stably bound peptide. This explains well-established links between accelerated MHCII protein turnover and impaired peptide loading. A model accounting for these findings is shown in Fig. 5B.

Mechanistic studies focused on the KG-1 model cell line, but the findings are likely to be more broadly applicable. Rescue of HLA-DR molecules by PepA was observed in immature MoDCs, a well-characterised APC type (57), which was previously shown to exhibit MHC class II protein turnover $(9,45)($ Fig. 1E, Fig. S3). PepA effects were seen in MoDC from unrelated donors, ${ }^{2}$ suggesting that various DR alleles are similarly susceptible to aspartyl proteases. This is consistent with the finding that CatD was found to attack the non-polymorphic DR $\alpha$ chain in vitro. PepA was also able to rescue murine MHCII molecules in splenic APCs, albeit with weaker effects in CD11c+ DCs than in B cells and some allele-dependence (Fig. S4). Residue F54 is conserved in the amino acid sequences of human and mouse MHCII $\alpha$ chains, albeit with variation in flanking sequences that may affect CatD susceptibility, potentially confining CatD susceptibility 
at this site to HLA-DR, -DP and H2-E $\alpha$ chains (Table S5). H2-A ${ }^{\mathrm{d}}$, which is CatD susceptible experimentally (Fig. S4), scores lower but has the highest score of the H2-A alleles at $\alpha \mathrm{F} 54$; uniquely among $\mathrm{H} 2-\mathrm{A}$ alleles, it has a potential alternative cleavage site at $\alpha$ L53, immediately adjacent in the same strand (Table S5).

Of the two aspartyl proteases, CatD, which is responsible for the PepA rescue in the KG1 model, co-localizes with MHCII in late endosomes and lysosomes, and it is therefore available to carry out MHCII protein degradation in any APC type $(34,37,40) .{ }^{4} \mathrm{CatE}$ shares sequence homology and sequence-dependent cleavage preferences with CatD (58) but, owing to its existence as a disulfide-bonded homodimer, may have more stringent steric requirements than the monomeric CatD; it is expressed in APCs but not found in late endosomes or lysosomes (39). In KG-1 cells, CatE expression was undetectable, and the PepA effect was clearly CatD-dependent, as shown by CatD knockdown. In vitro, evidence for CatE attack on recombinant soluble DR was weak. Nonetheless, we cannot exclude the possibility that CatE could contribute to MHCII degradation in APCs that express this enzyme.

Comparing the rate of DR turnover in MoDCs $\left(t_{1 / 2} \approx 1\right.$ day, equivalent to $50 \%$ new DR protein per day) with the rate of DR accumulation in PepA-treated MoDCs (25\% increase per day in standard media) suggested that aspartyl protease activity accounts for very approximately half of the observed rates of DR turnover in this system. The remainder could be accounted for by the existence of non-aspartyl proteases with redundant functions (see below) or by the loss of some MHCII molecules present on exosomes 
$(59,60)$. It is difficult, however, to rule out the alternative possibility that inhibition of CatD activity was incomplete at the maximal non-toxic dose of PepA used. In the lymphoblastoid cell line, Priess, lower CatD expression correlated with slower turnover ${ }^{3}$ and little if any DR rescue by PepA (Fig. 1F), compared with MoDCs, although other factors, such as ubiquitylation, may contribute to these differences (61).

Our data may help to explain how MHCII molecules survive proteolysis by CatD and other lysosomal enzymes during their maturation and peptide loading, yet are degraded in the same compartments. We propose that, during maturation, the site of initial CatD attack is protected by interactions with invariant chain, DM or bound peptide; in contrast, poor loading or loss of bound peptide may leave DR molecules vulnerable to CatD attack (Fig. 5C). Initial CatD attack occurs at residue $\alpha$ Phe54 (Fig. 3D), in an extended strand C-terminal to the $\alpha$-chain helix, which hydrogen-bonds with CLIP and antigenic peptides in MHCII crystal structures $(26,62,63)$. In addition, interaction with intact Ii prior to its degradation may sterically mask the vicinity of the CatD attack site by its trimerization domain, C-terminal to CLIP $(64,65)$. When DR binds to DM during peptide exchange (66), the extended strand around the site of CatD cleavage at $\alpha$ F54 changes conformation but remains sterically protected within the DM/DR complex. Thus, this site remains unavailable to CatD attack throughout all steps of the MHCII peptide loading pathway. These considerations may explain why, in KG-1 cells, DR molecules resisted CatD attack while associated with Ii, Ii fragments, or stably bound peptide. In contrast, other SDSunstable forms of DR (likely DR molecules with loosely bound peptide, or none) were vulnerable to CatD attack (Fig. 4). 
Molecular dynamics simulations of empty DR molecules, and biophysical studies of mutant DR molecules with altered peptide-exchange characteristics, suggest that the extended strand around $\alpha$ Phe54 gains conformational flexibility and, partly due to molecular movements in the opposing $\beta$-chain helix, becomes more accessible in peptidereceptive empty conformations (67-69). This would provide steric access for CatD to this part of the peptide-binding groove in empty molecules, explaining the selective degradation of such molecules. Intriguingly, $\alpha$ F54 is not only a key site of CatD attack, but is also implicated in these conformational changes by mutagenesis studies (69).

Only a small proportion of DR molecules could be degraded by CatD in vitro in our experiments. For other substrates, the optimal $\mathrm{pH}$ for $\mathrm{CatD}$ attack has been reported as pH2-3.5 (36,70), but we explored only lysosomal $\mathrm{pH}$ values (4.5-5.5), in order to maintain DR folding (71) and thus physiological relevance. The insect cell-derived recombinant soluble DR molecules used in these studies are not loaded with an edited, SDS-stable peptide repertoire, unlike native DR molecules purified from mammalian APC. Nonetheless, their peptide-binding grooves have been found to be at least partially occupied by polypeptides (72). In addition, kinetic and molecular dynamics studies suggest that peptide-receptive conformations are metastable, collapsing into inactive conformations (73), in which the strand on either side of residue $\alpha$ F54 moves into the peptide-binding groove $(69,74,75)$. Aggregation of empty MHCII molecules $(76,77)$ may also hinder CatD attack. Open, monomeric conformations that are vulnerable to CatD attack may therefore be rare. Taken together, these factors may help to explain why only 
a small percentage of DR molecules was degraded by recombinant $\mathrm{CatD}$ in vitro, and they may contribute to the slow rate of DR turnover in vivo. Although further experiments will be required to elucidate how peptide binding and conformational states influence the CatD susceptibility of HLA-DR, we hypothesise that initial CatD attack on HLA-DR at $\alpha$ F54 may selectively target an unstable, peptide-receptive conformation (Fig. 5C).

In vitro, CatD cleaved DR molecules not only after $\alpha \mathrm{F} 54$, but also after other large hydrophobic residues, producing smaller fragments (Fig. 3D); however, one of these residues is buried in the folded structure of DR, and a third is near the initial cleavage site; cleavage at these residues may reflect secondary degradation steps. In vivo, the DR polypeptides rescued from degradation by PepA were intact molecules rather than smaller degradation intermediates; this is consistent with the idea that CatD is important for initiating proteolytic attack, although it may also contribute to the downstream degradation steps, alongside other proteases.

DR molecules could become available for CatD attack at different times during their post-translational fate. The first opportunity for degradation would arise from a failure to acquire stable peptides following Ii processing, upon release of CLIP and dissociation from DM (Fig. 5C). Indeed, in cell lines with defective peptide loading due to DM deficiency, pulse-chase analysis shows some attrition of DR molecules relatively shortly after biosynthesis (24). However, the much longer half-life of bulk HLA-DR molecules and the slow kinetics of the PepA effect suggest that this is not the dominant pathway in 
the APC that we have studied. A subsequent opportunity for CatD attack would arise when, after a time of residence at the plasma membrane, DR molecules are ubiquitylated and re-internalised (14). We found no evidence that the DR molecules rescued by PepA in KG-1 cells remained ubiquitinated (which would have raised the molecular weight of the $\beta$-chain in PepA-treated cells); rather, any cytoplasmic oligo-ubiquitin chains may be removed by de-ubiquitinating enzymes prior to CatD attack on the ectodomains $(78,79)$. An unresolved question is whether the remarkable selectivity for SDS-unstable, Ii-nonassociated DR molecules (Fig. 4) is exclusively due to the inherent specificity of CatD, or whether, in addition, ubiquitin-dependent internalisation selectively targets DR molecules that have lost bound peptide for lysosomal degradation (Fig. 5B).

Several findings indicated that KG-1 cells restore HLA-DR levels to wild-type after prolonged inhibition (Fig. S2A) or genetic ablation (Fig. 2D) of CatD. Conceivably, new HLA-DR synthesis could slow down to match the reduced rate of degradation.

Alternatively, lysosomal overload caused by a lack of CatD activity could prompt the induction of other lysosomal enzymes that compensate for the defect. A possible precedent for the latter mechanism has been found, albeit in the opposite direction: CatD levels were shown to be elevated in the skin of CatL-deficient mice (80). Adaptation to a chronic lack of active CatD might help to explain why previous studies in CatD knockout mice (40) and genome-wide screens for modifiers of DR expression (32) have failed to detect the role of CatD in DR degradation identified here. In those studies, there would have been ample time for adaptive mechanisms to compensate for the lack of CatD. For the same reason, genetic studies of spontaneous or engineered defects in lysosomal 
proteases might underestimate their roles in normal biology. In human neuronal ceroid lipofuscinosis, a severe congenital lysosomal storage disorder attributed to hypomorphic mutations in CTSD (CatD gene; OMIM entry 116840), the neurodevelopmental consequences of CatD insufficiency dominate the clinical manifestations, and any immune abnormalities may be comparatively minor or masked by adaptation, or both.

MHCII allelic variation is a major determinant of autoimmune disease risk (22,81-83). Instability of the disease-associated MHCII alleles has been proposed as a mechanism for impaired tolerance in NOD mice and human T1D patients with HLA-DQ risk alleles (7). Recent studies from our laboratory, however, using ${ }^{2} \mathrm{H}_{2} \mathrm{O}$ labelling techniques to quantify turnover in NOD APCs in vivo, found no evidence for an intrinsic stability defect of the risk alleles, and no correlation with autoimmunity $(7,8)$. The present study shows that CatD attack on HLA-DR involves a monomorphic cleavage site (Fig. 3), and our unpublished studies show little variation in HLA-DR half-lives between individuals. ${ }^{2}$ Both findings argue against a major role for allelic differences in DR protein turnover in HLA-DRB1-linked risk of autoimmunity. Moreover, if our findings in KG-1 cells are representative of physiological APCs, blocking of DR protein degradation by CatD would not restore any presentation defect, as the rescued DR molecules accumulate intracellularly, and thus would not contribute to antigen presentation even if they were weakly bound to self-peptides.

\section{Concluding remarks}


We found that CatD initiates HLA-DR degradation by selective cleavage at a site whose susceptibility to attack is affected by interactions with Ii, DM and peptide loading. CatD acts selectively on DR molecules lacking bound Ii or stably bound peptide, providing a means of lysosomal quality control. The data explain how HLA-DR molecules resist degradation during their maturation but are degraded in APCs as needed. They argue against a role of allelic differences in HLA-DR protein instability as a mechanism of DRB1 gene associations with autoimmunity. Our work raises novel questions about the molecular mechanisms linking HLA-DR peptide-loading state to internalization vs. degradation. Adaptive mechanisms may exist that restore wild-type DR levels in cells lacking CatD activity. The ability to trap HLA-DR molecules that would otherwise be degraded will enable further dissection of this immunologically important disposal pathway. 


\section{Experimental Procedures}

\section{Cell culture and inhibitor studies}

Priess is a DRB1*04:01-homozygous lymphoblastoid cell line (84). KG-1 is an acute myleloid leukemia cell line (85) with features resembling immature DCs $(86,87)$, expressing DRB $1 * 11$ and $* 14(88)$. Cells were grown at $37^{\circ} \mathrm{C}$ in a humidified incubator, in RPMI1640 medium supplemented with 10\% FBS, 2 mM L-glutamine, and penicillin/streptomycin, except for KG-1 cells, which were grown in IMDM with $20 \%$ FBS, penicillin/streptomycin, glutamine, and $25 \mathrm{mM}$ HEPES. In some experiments, 2 mM L-glutamine was replaced by $1 \%$ v/v GlutaMax (L-alanyl-L-glutamine)(89). For inhibitor studies, triplicate cultures were set up with $20 \mu \mathrm{M}$ PepA (diluted from $5 \mathrm{mM}$ stock in DMSO), with an equivalent volume of DMSO as a vehicle control. These conditions did not interfere with the growth kinetics (by hemocytometer counting) or scatter profile (by flow cytometry) of KG-1 cells. Alternatively, cells were treated with $10 \mu \mathrm{M}$ Pepstatin A-penetratin (diluted from $1 \mathrm{mM}$ stock in PBS), a membrane-permeant cationic peptide conjugate of PepA with greater intracellular bioavailability (90). Cells were harvested up to 72 hours thereafter for analysis.

\section{Lentiviral shRNA knockdown}

A commercial MISSION CTSD shRNA construct in pLKO.1-puro vector (MISSION, Sigma-Aldrich) was used for CatD knockdown; empty vector was used as a negative control. KG- 1 cells $\left(2.5 \times 10^{5}\right.$ in $200 \mu \mathrm{l}$ media) were treated with $8 \mu \mathrm{g} / \mathrm{ml}$ polybrene overnight in a flat-bottom 96-well plate. Lentiviral supernatants were added at MOI 5 and the plate centrifuged at room temperature for $30 \mathrm{~min}$. at $500 \times \mathrm{g}$. Cells were expanded 
into larger plates, selected with $1 \mu \mathrm{g} / \mathrm{ml}$ puromycin, and expanded further into culture flasks for experiments.

\section{$\underline{\text { Monocyte-derived dendritic cell culture }}$}

Monocyte-derived dendritic cells were derived from healthy donor blood as described (45) with modifications as follows. Briefly, volunteers were recruited with ethical approval (Cambridge Research Ethics Committee 01/363) and informed consent in accordance with the Declaration of Helsinki. Heparinised venous blood (10 ml) was withdrawn, and mononuclear cells were isolated over Ficoll gradients. $\mathrm{CD} 14^{+}$monocytes were immunomagnetically enriched using Miltenyi CD14 microbeads and cultured for 6 days in complete RPMI media with GM-CSF and IL-4, yielding CD11 ${ }^{+}$CD14- MoDCs that were phenotypically immature $\left(\mathrm{CD} 86^{\text {low }}, \mathrm{HLA}-\mathrm{DR}{ }^{\text {low }}\right)$ as reported earlier (supplemental data in (45)). They were treated with $20 \mu \mathrm{M}$ PepA or DMSO vehicle for another 24 hours. The LPS antagonist, polymyxin B $(20 \mu \mathrm{g} / \mathrm{ml})(91)$, was added $1 \mathrm{~h}$ before inhibitor treatment to minimize any inadvertent LPS activation.

\section{Quantitative real-time RT-PCR analysis}

RNA was isolated from $10^{5} \mathrm{KG}-1$ or Priess cells, reverse-transcribed and PCR-amplified using the Power SYBR Green Cells-to-Ct Kit (Life Technologies). Quantitative real-time PCR was performed in 96-well plates using the SYBR Green method and a Step One Plus qPCR instrument (Applied Biosystems). After 10 min. at $95^{\circ} \mathrm{C}$ for enzyme activation, 30 cycles of denaturation $\left(95{ }^{\circ} \mathrm{C}, 15 \mathrm{~s}\right)$, annealing $\left(55-60{ }^{\circ} \mathrm{C}\right.$ optimised for each primer set, $1 \mathrm{~min}$.), and extension $\left(72{ }^{\circ} \mathrm{C}, 15 \mathrm{~s}\right)$ were performed, followed by a melt 
curve at a heating rate of $1{ }^{\circ} \mathrm{C}$ per min. Primers for CatD, CatE, and GAPDH

(housekeeping control) were as described (92-94); predicted amplicon sizes were, respectively, 296, 500 and 206 bp. PCR products were resolved by $0.7 \%$ agarose gel electrophoresis in TBE (70V, 90 min.), alongside a 100-bp DNA ladder (Promega), and visualized using SYBR Safe dye (Invitrogen) and a LiCor Odyssey Fc imager.

$\underline{\text { Immunofluorescent staining and flow cytometry }}$

For surface staining, human cells were suspended in phosphate-buffered saline (PBS) with $1 \%$ BSA and $0.05 \%$ sodium azide (FACS buffer), blocked for 15 min. with $10 \%$ normal mouse serum, and incubated with saturating concentrations of anti-HLA-DR mAb-FITC conjugate (BioLegend)(95) for 30-60 minutes. Cells were washed in FACS buffer and analysed immediately or, after washing in PBS, fixed in Cytofix (BD) for later analysis. The mAb clone used, L243, reacts poorly, if at all, with MHCII $\alpha \beta$ dimers that are associated with full-length Ii but well with subsequent maturation stages (49,96-99).

For total (surface plus intracellular) DR staining, cells were washed in PBS, fixed and permeabilized using the Cytofix/Cytoperm kit (BD), washed in $1 \times$ Perm/Wash buffer, and subsequently processed as for live staining, except that all reagents were diluted, and cells washed, in $1 \times$ Perm/Wash buffer. PIN.1, an IgG1 mAb to the human Ii cytoplasmic tail (Santa Cruz Biotechnologies)(99), was used to detect Ii. CatD was detected by indirect staining, using primary polyclonal rabbit anti-CatD IgG (Abcam; ab75852) and secondary APC-conjugated anti-rabbit IgG. Unstained, secondary antibody alone, and isotype control stains were included as appropriate. 
Flow cytometric analysis was performed using either FACSCantoII or Accuri C6 flow cytometers (BD). Data were acquired for at least 5000 cells per sample, with gating for intact singlet cells, and median fluorescence values were determined.

\section{$\underline{\text { Analysis of murine splenocytes }}$}

Animal studies were performed in accordance with institutional and UK Home Office ethical and licencing requirements (Project Licence 80/2156). Pre-diabetic nonobese diabetic (NOD, expressing $\left.\mathrm{H}-2 \mathrm{~A}^{\mathrm{g} 7}\right)$ and Balb/c $\left(\mathrm{H}-2 \mathrm{~A}^{\mathrm{d}}, \mathrm{E}^{\mathrm{d}}\right)$ mice were crossed and $\mathrm{F} 1$ offspring aged to 6 weeks (8). After $\mathrm{CO}_{2}$ asphyxiation and cervical dislocation, spleens were removed and splenocyte suspensions obtained aseptically by Liberase CI (Roche) digestion, according to manufacturer's instructions, followed by passage through a $70 \mu \mathrm{m}$ mesh. Splenocytes were cultured in complete RPMI for 24 hours with $20 \mu \mathrm{M}$ PepA or vehicle as described above. For flow cytometric analysis, cells were stained for DC (CD11c) and B-cell (B220) lineage antigens and, after fixation and permeabilization, with mAbs specific for each of the three MHCII molecules (8).

\section{$\underline{\text { Western blot }}$}

Using modifications of previously-described protocols (49), cell pellets were extracted in RIPA buffer (100) with Roche Complete protease inhibitors, normalised for protein content using bicinchoninic acid (BCA) protein assay, mixed with SDS-PAGE sample buffer, boiled for 5 minutes, and run on 12\% SDS-PAGE mini-gels (Bio-Rad). For SDS stability assays, the boiling step was omitted where indicated. Resolved proteins were 
transferred to PVDF membranes, which were blocked with 5\% nonfat dry milk in PBS, probed with antibodies to monomorphic determinants of HLA-DR $\alpha$ and $\beta$ chains (mAbs DA6.147 and DA2, respectively, both from Santa Cruz Biotechnologies)(101,102), invariant chain (mAb PIN.1, see above), CatD (mAb 185111, R\&D Systems) or CatE (polyclonal goat IgG, Cat. No. AF1294, R\&D Systems). Some blots were stripped and reprobed with mAb against GAPDH (Santa Cruz Biotechnologies) as a loading control. Bound antibody was visualised using appropriate HRP-conjugated second-step reagents, chemiluminescent detection, and LiCOR Odyssey Fc imaging and band quantification.

\section{$\underline{\text { In vitro digestion }}$}

Recombinant soluble HLA-DR0402 proteins (ectodomains encoded by DRA and DRB1*04:02) (103) were produced in insect cells and purified from culture supernatants by L243-sepharose immunoaffinity chromatography as described (71). Recombinant human prepro-cathepsins D and E (R\&D Systems) were preincubated for auto-activation as per manufacturer's recommendations (e.g., for CatD, $20 \mu \mathrm{g} / \mathrm{ml}$ enzyme in $0.1 \mathrm{M}$ sodium acetate buffer, $0.2 \mathrm{M} \mathrm{NaCl}, \mathrm{pH} 3.5 ; 30 \mathrm{~min}$. at $\left.37{ }^{\circ} \mathrm{C}\right)$. Purified DR0402 $(4 \mu \mathrm{g} / 3$ $\mu \mathrm{l}$ PBS/reaction) was digested with $4 \mathrm{ng} / 2 \mu \mathrm{l}$ activated CatD or E (or buffer control), diluted to $20 \mathrm{ul}$ in assay buffer (final $\mathrm{pH} 4.5$ ). Where indicated, excess PepA was added before the enzyme $\left(7 \mathrm{nmol} / 1 \mu \mathrm{l}\right.$ ethanol). Samples were incubated at $37{ }^{\circ} \mathrm{C}$ for 16 hours, neutralized with 1.5 M Tris-HCl, pH 8.8. Samples were resolved by SDS-PAGE and proteins visualized by silver staining. Bands were excised for LC/MS analysis. 


\section{Mass spectrometry}

Bands of interest were subjected to in-gel tryptic digestion and analysed by UPLCMS/MS on an Orbitrap Velos mass spectrometer as previously described $(45,104)$. For the identification of CatD cleavage products, we exploited the orthogonal cleavage specificities of trypsin (after Lys/Arg) and CatD (after large hydrophobic residues $(58,105)$ (www.ebi.ac.uk/MEROPS database entry A01.009 (106)). High-resolution $(30,000)$ Orbitrap Velos LC-MS/MS data files for tryptic digests of the intact DR $\alpha$ and $\beta$ chains or specific cleavage products were screened, using MASCOT (Matrix Science), for matches to the sequences of the sDR0402 $\alpha$ and $\beta$ chains (103), and the identified fragments were aligned to the DRA*01:01 and DRB1*04:02 ectodomain protein sequences from the IMGT/HLA database (https://www.ebi.ac.uk/ipd/imgt/hla/)(107). In addition to tryptic fragments, we screened for novel fragments that were not observed in the parent polypeptides, representing CatD cleavage.

\section{$\underline{\text { Protein structure analysis and visualization }}$}

Human HLA-DR, -DP and -DQ $\alpha$-chain sequences were obtained from the IMGT HLA database. Murine $\mathrm{H} 2-\mathrm{A}$ and $-\mathrm{E} \alpha$-chain sequences were from the NCBI protein database (https://ncbi.nlm.nih.gov/protein). Protein structures were from the RCSB Protein Data Bank (https://www.rcsb.org/). Alignment of sequences (residues 41-70, mature DR $\alpha$ protein sequence numbering) was performed after inspection of crystal structures of DR, DQ and H-2A complexed with CLIP (PDB accession numbers 3QXA; 1A6A; 5KSU; 1MUJ). Putative CatD cleavage sites were visualized in the crystal structure of DR1CLIP (3QXA) using CCP4MG software (http://www.ccp4.ac.uk/MG/)(108). 


\section{Prediction of CatD cleavage from sequence}

To check the plausibility of the experimentally identified cleavages, the observed CatD cleavage sites were compared with sequence-dependent predicted CatD cleavage probabilities, calculated in Microsoft Excel using input from the MEROPS database (106). Briefly, the frequencies of the 20 amino acids within an 8-residue window (P4 to P4') around the cleavage site were obtained from the MEROPS specificity matrix for CatD. They were converted to probabilities and scaled by dividing by $5 \%$ (expectation value for 1 of 20 amino acids) to obtain scores for their over- or under-representation within CatD cleavage sites. For every potential cleavage site, the scores of the amino acid residues within the P4-to-P4' sliding window were multiplied to obtain a cleavage likelihood score. An example of the computation is shown in Tables S2-S4 and related supporting text.

\section{$\underline{\text { Data analysis }}$}

Flow cytometry data were processed in FlowJo or CSampler software. Band intensities on Western blots were quantified using LiCor Odyssey Fc ImageStudio software. Numerical data and descriptive statistics were processed in Microsoft Excel, and gel images exported into PowerPoint for annotation. Inferential statistics (cf. figure legends) were performed with IBM SPSS, R, or GraphPad Prism. 


\section{Data availability}

All data are contained within the manuscript.

\section{Acknowledgements}

We thank the Phenotyping Hub of the Cambridge Biomedical Research Centre and the Department of Life Sciences, University of Roehampton, for access to flow cytometers.

We are grateful for expert technical support and provision of critical reagents and services by staff in the Department of Life Sciences at the University of Roehampton; the Division of Human Gene Therapy, Department of Pediatrics at Stanford University Medical Center; and the Division of Rheumatology, Department of Medicine and the Cambridge Centre for Proteomics at the University of Cambridge. Dr Claudia Prevosto and Aleksandra Gumienny generated unpublished data mentioned in this paper. We thank Professor J.S. Hill Gaston for facilitating the recruitment of healthy human subjects and for critically reading the manuscript, and Dr Timo Burster for early discussions.

\section{Author contributions}

Conceptualization: RB, SM

Data curation: RB, NS, MJD

Formal Analysis: RB, NS, ADR, MJD

Funding acquisition: RB Investigation: NS, SM, CTAP, RWMR, AO, ADR, MJD, RB

Methodology: RB, ADR

Project administration: RB

Resources: EDM, MJD

Supervision: RB, MJD, EDM

Visualization: NS, SM, CTAP, RWMR, AO, ADR, RB

Writing - original draft: RB

Writing - review \& editing: all coauthors 


\section{Funding and additional information}

We are grateful for financial support from Versus Arthritis (formerly Arthritis Research

UK; Senior Research Fellowship, ref. 18543, and Research Progression Award, ref.

20648), Diabetes UK (Small Grant), the MS Society (Project Grant, ref. 42), and the

University of Roehampton (all to RB) and NIH AI095813 (to EDM). NS was supported

by a MS International Federation McDonald fellowship for part of this work.

The content is solely the responsibility of the authors and does not necessarily represent the official views of the National Institutes of Health.

\section{Disclosures}

The authors declare that they have no conflicts of interest with the contents of this article. 


\section{References}

1. Wang, J. H., and Reinherz, E. L. (2012) The structural basis of alphabeta Tlineage immune recognition: TCR docking topologies, mechanotransduction, and co-receptor function. Immunol Rev 250, 102-119

2. LeibundGut-Landmann, S., Waldburger, J. M., Krawczyk, M., Otten, L. A., Suter, T., Fontana, A., Acha-Orbea, H., and Reith, W. (2004) Mini-review: Specificity and expression of CIITA, the master regulator of MHC class II genes. Eur J Immunol 34, 1513-1525

3. Choi, N. M., Majumder, P., and Boss, J. M. (2011) Regulation of major histocompatibility complex class II genes. Current opinion in immunology 23, 8187

4. Busch, R., and Mellins, E. D. (1996) Developing and shedding inhibitions: How MHC class II molecules reach maturity. Current Opinion in Immunology 8, 51-58

5. Neefjes, J., Jongsma, M. L., Paul, P., and Bakke, O. (2011) Towards a systems understanding of MHC class I and MHC class II antigen presentation. Nat Rev Immunol 11, 823-836

6. Blum, J. S., Wearsch, P. A., and Cresswell, P. (2013) Pathways of antigen processing. Annu Rev Immunol 31, 443-473

7. De Riva, A., and Busch, R. (2013) MHC Class II Protein Turnover In vivo and Its Relevance for Autoimmunity in Non-Obese Diabetic Mice. Front Immunol 4, 399

8. De Riva, A., Varley, M. C., Bluck, L. J., Cooke, A., Deery, M. J., and Busch, R. (2013) Accelerated turnover of MHC class II molecules in nonobese diabetic mice is developmentally and environmentally regulated in vivo and dispensable for autoimmunity. J Immunol 190, 5961-5971

9. Cella, M., Engering, A., Pinet, V., Pieters, J., and Lanzavecchia, A. (1997) Inflammatory stimuli induce accumulation of MHC class II complexes on dendritic cells. Nature 388, 782-787

10. Pierre, P., Turley, S. J., Gatti, E., Hull, M., Meltzer, J., Mirza, A., Inaba, K., Steinman, R. M., and Mellman, I. (1997) Developmental regulation of MHC class II transport in mouse dendritic cells. Nature 388, 787-792

11. Shin, J. S., Ebersold, M., Pypaert, M., Delamarre, L., Hartley, A., and Mellman, I. (2006) Surface expression of MHC class II in dendritic cells is controlled by regulated ubiquitination. Nature 444, 115-118

12. van Niel, G., Wubbolts, R., Ten Broeke, T., Buschow, S. I., Ossendorp, F. A., Melief, C. J., Raposo, G., van Balkom, B. W., and Stoorvogel, W. (2006) Dendritic cells regulate exposure of MHC class II at their plasma membrane by oligoubiquitination. Immunity 25, 885-894

13. De Gassart, A., Camosseto, V., Thibodeau, J., Ceppi, M., Catalan, N., Pierre, P., and Gatti, E. (2008) MHC class II stabilization at the surface of human dendritic cells is the result of maturation-dependent MARCH I down-regulation. Proc Natl Acad Sci U S A 105, 3491-3496

14. Walseng, E., Furuta, K., Bosch, B., Weih, K. A., Matsuki, Y., Bakke, O., Ishido, S., and Roche, P. A. (2010) Ubiquitination regulates MHC class II-peptide 
complex retention and degradation in dendritic cells. Proc Natl Acad Sci U S A 107, 20465-20470

15. Obst, R., van Santen, H. M., Melamed, R., Kamphorst, A. O., Benoist, C., and Mathis, D. (2007) Sustained antigen presentation can promote an immunogenic T cell response, like dendritic cell activation. Proc Natl Acad Sci U S A 104, 1546015465

16. Han, S., Asoyan, A., Rabenstein, H., Nakano, N., and Obst, R. (2010) Role of antigen persistence and dose for CD4+ T-cell exhaustion and recovery. Proc Natl Acad Sci U S A 107, 20453-20458

17. Galbas, T., Steimle, V., Lapointe, R., Ishido, S., and Thibodeau, J. (2012) MARCH1 down-regulation in IL-10-activated B cells increases MHC class II expression. Cytokine 59, 27-30

18. Mittal, S. K., Cho, K. J., Ishido, S., and Roche, P. A. (2015) Interleukin 10 (IL10)-mediated Immunosuppression: MARCH-I induction regulates antigen presentation by macrophages but not dendritic cells. J Biol Chem 290, 2715827167

19. Bannard, O., McGowan, S. J., Ersching, J., Ishido, S., Victora, G. D., Shin, J. S., and Cyster, J. G. (2016) Ubiquitin-mediated fluctuations in MHC class II facilitate efficient germinal center B cell responses. J Exp Med 213, 993-1009

20. Nelson, C. A., Petzold, S. J., and Unanue, E. R. (1994) Peptides determine the lifespan of MHC class II molecules in the antigen-presenting cell. Nature 371, 250-252

21. Busch, R., Rinderknecht, C. H., Roh, S., Lee, A. W., Harding, J. J., Burster, T., Hornell, T. M., and Mellins, E. D. (2005) Achieving stability through editing and chaperoning: regulation of MHC class II peptide binding and expression.

Immunol Rev 207, 242-260

22. Busch, R., De Riva, A., Hadjinicolaou, A. V., Jiang, W., Hou, T., and Mellins, E. D. (2012) On the perils of poor editing: Regulation of peptide loading by HLADQ and H2-A molecules associated with celiac disease and type 1 diabetes.

Expert reviews in molecular medicine 14, e15-e15

23. Rinderknecht, C. H., Lu, N., Crespo, O., Truong, P., Hou, T., Wang, N., Rajasekaran, N., and Mellins, E. D. (2010) I-Ag7 is subject to post-translational chaperoning by CLIP. Int Immunol 22, 705-716

24. Rinderknecht, C. H., Roh, S., Pashine, A., Belmares, M. P., Patil, N. S., Lu, N., Truong, P., Hou, T., Macaubas, C., Yoon, T., Wang, N., Busch, R., and Mellins, E. D. (2010) DM influences the abundance of major histocompatibility complex class II alleles with low affinity for class II-associated invariant chain peptides via multiple mechanisms. Immunology 131, 18-32

25. Rinderknecht, C. H., Belmares, M. P., Catanzarite, T. L., Bankovich, A. J., Holmes, T. H., Garcia, K. C., Nanda, N. K., Busch, R., Kovats, S., and Mellins, E. D. (2007) Posttranslational regulation of I-Ed by affinity for CLIP. J Immunol 179, 5907-5915

26. Painter, C. A., and Stern, L. J. (2012) Conformational variation in structures of classical and nonclassical MHCII proteins and functional implications.

Immunological reviews 250, 144-157 
27. Reich, Z., Altman, J. D., Boniface, J. J., Lyons, D. S., Kozono, H., Ogg, G., Morgan, C., and Davis, M. M. (1997) Stability of empty and peptide-loaded class II major histocompatibility complex molecules at neutral and endosomal $\mathrm{pH}$ : comparison to class I proteins. Proc Natl Acad Sci U S A 94, 2495-2500

28. Kaufman, J. F., and Strominger, J. L. (1979) Both chains of HLA-DR bind to the membrane with a penultimate hydrophobic region and the heavy chain is phosphorylated at its hydrophilic carboxyl terminus. Proc Natl Acad Sci U S A 76, 6304-6308

29. Kaufman, J. F., and Strominger, J. L. (1983) The extracellular region of light chains from human and murine MHC class II antigens consists of two domains. $J$ Immunol 130, 808-817

30. Herrmann, T. L., Agrawal, R. S., Connolly, S. F., McCaffrey, R. L., Schlomann, J., and Kusner, D. J. (2007) MHC Class II levels and intracellular localization in human dendritic cells are regulated by calmodulin kinase II. J Leukoc Biol 82, 686-699

31. Burster, T., Macmillan, H., Hou, T. Y., Schilling, J., Truong, P., Boehm, B. O., Zou, F., Lau, K., Strohman, M., Schaffert, S., Busch, R., and Mellins, E. D. (2010) Masking of a cathepsin $\mathrm{G}$ cleavage site in vivo contributes to the proteolytic resistance of major histocompatibility complex class II molecules. Immunology 130, 436-446

32. Paul, P., van den Hoorn, T., Jongsma, Marlieke L. M., Bakker, Mark J., Hengeveld, R., Janssen, L., Cresswell, P., Egan, David A., van Ham, M., ten Brinke, A., Ovaa, H., Beijersbergen, Roderick L., Kuijl, C., and Neefjes, J. (2011) A Genome-wide Multidimensional RNAi Screen Reveals Pathways Controlling MHC Class II Antigen Presentation. Cell 145, 268-283

33. Nakagawa, T. Y., and Rudensky, A. Y. (1999) The role of lysosomal proteinases in MHC class II-mediated antigen processing and presentation. Immunol Rev 172, 121-129

34. Moss, C. X., Villadangos, J. A., and Watts, C. (2005) Destructive potential of the aspartyl protease cathepsin D in MHC class II-restricted antigen processing. Eur J Immunol 35, 3442-3451

35. Burster, T., Macmillan, H., Hou, T., Boehm, B. O., and Mellins, E. D. (2010) Cathepsin G: roles in antigen presentation and beyond. Mol Immunol 47, 658-665

36. Marciniszyn, J., Jr., Hartsuck, J. A., and Tang, J. (1976) Mode of inhibition of acid proteases by pepstatin. J Biol Chem 251, 7088-7094

37. Saku, T., Sakai, H., Shibata, Y., Kato, Y., and Yamamoto, K. (1991) An immunocytochemical study on distinct intracellular localization of cathepsin $\mathrm{E}$ and cathepsin D in human gastric cells and various rat cells. J Biochem 110, 956964

38. Finley, E. M., and Kornfeld, S. (1994) Subcellular localization and targeting of cathepsin E. J Biol Chem 269, 31259-31266

39. Zaidi, N., and Kalbacher, H. (2008) Cathepsin E: a mini review. Biochem Biophys Res Commun 367, 517-522

40. Deussing, J., Roth, W., Saftig, P., Peters, C., Ploegh, H. L., and Villadangos, J. A. (1998) Cathepsins B and D are dispensable for major histocompatibility complex 
class II-mediated antigen presentation. Proceedings of the National Academy of Sciences of the United States of America 95, 4516-4521

41. Pilzner, C., Buhling, F., Reinheckel, T., Chwieralski, C., Rathinasamy, A., Lauenstein, H. D., Wex, T., Welte, T., Braun, A., and Groneberg, D. A. (2012) Allergic airway inflammation in mice deficient for the antigen-processing protease cathepsin E. Int Arch Allergy Immunol 159, 367-383

42. Z Zhang, T., Maekawa, Y., Hanba, J., Dainichi, T., Nashed, B. F., Hisaeda, H., Sakai, T., Asao, T., Himeno, K., Good, R. A., and Katunuma, N. (2000) Lysosomal cathepsin B plays an important role in antigen processing, while cathepsin $\mathrm{D}$ is involved in degradation of the invariant chain inovalbuminimmunized mice. Immunology 100, 13-20

43. Slivac, I., Blajić, V., Radošević, K., Kniewald, Z., and Gaurina Srček, V. (2010) Influence of different ammonium, lactate and glutamine concentrations on CCO cell growth. Cytotechnology 62, 585-594

44. Ten Broeke, T., De Graaff, A., Van't Veld Esther, M., Wauben Marca, H. M., Stoorvogel, W., and Wubbolts, R. (2010) Trafficking of MHC Class II in Dendritic Cells is Dependent on but Not Regulated by Degradation of Its Associated Invariant Chain. Traffic 11, 324-331

45. Prevosto, C., Usmani, M. F., McDonald, S., Gumienny, A. M., Key, T., Goodman, R. S., Gaston, J. S. H., Deery, M. J., and Busch, R. (2016) Allele-Independent Turnover of Human Leukocyte Antigen (HLA) Class Ia Molecules. PLOS ONE 11, e0161011

46. Azuma, T., Pals, G., Mohandas, T. K., Couvreur, J. M., and Taggart, R. T. (1989) Human gastric cathepsin E. Predicted sequence, localization to chromosome 1, and sequence homology with other aspartic proteinases. J Biol Chem 264, 1674816753

47. Sallusto, F., Cella, M., Danieli, C., and Lanzavecchia, A. (1995) Dendritic cells use macropinocytosis and the mannose receptor to concentrate macromolecules in the major histocompatibility complex class II compartment: downregulation by cytokines and bacterial products. J Exp Med 182, 389-400

48. Kleijmeer, M. J., Ossevoort, M. A., van Veen, C. J., van Hellemond, J. J., Neefjes, J. J., Kast, W. M., Melief, C. J., and Geuze, H. J. (1995) MHC class II compartments and the kinetics of antigen presentation in activated mouse spleen dendritic cells. J Immunol 154, 5715-5724

49. Busch, R., Doebele, R. C., von Scheven, E., Fahrni, J., and Mellins, E. D. (1998) Aberrant intermolecular disulfide bonding in a mutant HLA-DM molecule: implications for assembly, maturation, and function. J Immunol 160, 734-743

50. Natarajan, S. K., Stern, L. J., and Sadegh-Nasseri, S. (1999) Sodium dodecyl sulfate stability of HLA-DR1 complexes correlates with burial of hydrophobic residues in pocket 1. J Immunol 162, 3463-3470

51. Sadegh-Nasseri, S., Natarajan, S., Chou, C.-L., Hartman, I. Z., Narayan, K., and Kim, A. (2010) Conformational heterogeneity of MHC class II induced upon binding to different peptides is a key regulator in antigen presentation and epitope selection. Immunologic research 47, 56-64 
52. Marić, M. A., Taylor, M. D., and Blum, J. S. (1994) Endosomal aspartic proteinases are required for invariant-chain processing. Proceedings of the National Academy of Sciences of the United States of America 91, 2171-2175

53. Riese, R. J., Wolf, P. R., Bromme, D., Natkin, L. R., Villadangos, J. A., Ploegh, H. L., and Chapman, H. A. (1996) Essential role for cathepsin S in MHC class IIassociated invariant chain processing and peptide loading. Immunity 4, 357-366

54. Villadangos, J. A., Riese, R. J., Peters, C., Chapman, H. A., and Ploegh, H. L. (1997) Degradation of Mouse Invariant Chain: Roles of Cathepsins S and D and the Influence of Major Histocompatibility Complex Polymorphism. The Journal of Experimental Medicine 186, 549-560

55. Costantino, C. M., Hang, H. C., Kent, S. C., Hafler, D. A., and Ploegh, H. L. (2008) Lysosomal cysteine and aspartic proteases are heterogeneously expressed and act redundantly to initiate human invariant chain degradation. J Immunol 180, 2876-2885

56. Sette, A., Southwood, S., Miller, J., and Appella, E. (1995) Binding of major histocompatibility complex class II to the invariant chain-derived peptide, CLIP, is regulated by allelic polymorphism in class II. J Exp Med 181, 677-683

57. Sallusto, F., and Lanzavecchia, A. (1994) Efficient presentation of soluble antigen by cultured human dendritic cells is maintained by granulocyte/macrophage colony-stimulating factor plus interleukin 4 and downregulated by tumor necrosis factor alpha. $J$ Exp Med 179, 1109-1118

58. Arnold, D., Keilholz, W., Schild, H., Dumrese, T., Stevanovic, S., and Rammensee, H. G. (1997) Substrate specificity of cathepsins D and E determined by N-terminal and C-terminal sequencing of peptide pools. Eur J Biochem 249, 171-179

59. Buschow, S. I., Nolte-'t Hoen, E. N., van Niel, G., Pols, M. S., ten Broeke, T., Lauwen, M., Ossendorp, F., Melief, C. J., Raposo, G., Wubbolts, R., Wauben, M. H., and Stoorvogel, W. (2009) MHC II in dendritic cells is targeted to lysosomes or T cell-induced exosomes via distinct multivesicular body pathways. Traffic 10, $1528-1542$

60. Zeng, F., and Morelli, A. E. (2018) Extracellular vesicle-mediated MHC crossdressing in immune homeostasis, transplantation, infectious diseases, and cancer. Semin Immunopathol 40, 477-490

61. Ma, J. K., Platt, M. Y., Eastham-Anderson, J., Shin, J. S., and Mellman, I. (2012) MHC class II distribution in dendritic cells and $\mathrm{B}$ cells is determined by ubiquitin chain length. Proc Natl Acad Sci U S A 109, 8820-8827

62. Ghosh, P., Amaya, M., Mellins, E., and Wiley, D. C. (1995) The structure of an intermediate in class II MHC maturation: CLIP bound to HLA-DR3. Nature 378, 457-462

63. Stern, L. J., Brown, J. H., Jardetzky, T. S., Gorga, J. C., Urban, R. G., Strominger, J. L., and Wiley, D. C. (1994) Crystal structure of the human class II MHC protein HLA-DR1 complexed with an influenza virus peptide. Nature 368, 215 221

64. Jasanoff, A., Park, S. J., and Wiley, D. C. (1995) Direct observation of disordered regions in the major histocompatibility complex class II-associated invariant chain. Proc Natl Acad Sci U S A 92, 9900-9904 
65. Jasanoff, A., Wagner, G., and Wiley, D. C. (1998) Structure of a trimeric domain of the MHC class II-associated chaperonin and targeting protein Ii. EMBO J 17, 6812-6818

66. Pos, W., Sethi, D. K., Call, M. J., Schulze, M.-S. E. D., Anders, A.-K., Pyrdol, J., and Wucherpfennig, K. W. (2012) Crystal Structure of the HLA-DM - HLA-DR1 Complex Defines Mechanisms for Rapid Peptide Selection. Cell 151, 1557-1568

67. Yaneva, R., Springer, S., and Zacharias, M. (2009) Flexibility of the MHC class II peptide binding cleft in the bound, partially filled, and empty states: a molecular dynamics simulation study. Biopolymers 91, 14-27

68. Wieczorek, M., Sticht, J., Stolzenberg, S., Gunther, S., Wehmeyer, C., El Habre, Z., Alvaro-Benito, M., Noe, F., and Freund, C. (2016) MHC class II complexes sample intermediate states along the peptide exchange pathway. Nat Commun 7, 13224

69. Painter, C. A., Negroni, M. P., Kellersberger, K. A., Zavala-Ruiz, Z., Evans, J. E., and Stern, L. J. (2011) Conformational lability in the class II MHC 310 helix and adjacent extended strand dictate HLA-DM susceptibility and peptide exchange. Proc Natl Acad Sci U S A 108, 19329-19334

70. Barrett, A. J. (1970) Cathepsin D. Purification of isoenzymes from human and chicken liver. Biochem J 117, 601-607

71. Busch, R., Reich, Z., Zaller, D. M., Sloan, V., and Mellins, E. D. (1998)

Secondary structure composition and $\mathrm{pH}$-dependent conformational changes of soluble recombinant HLA-DM. J Biol Chem 273, 27557-27564

72. Aichinger, G., Karlsson, L., Jackson, M. R., Vestberg, M., Vaughan, J. H., Teyton, L., Lechler, R. I., and Peterson, P. A. (1997) Major histocompatibility complex class II-dependent unfolding, transport, and degradation of endogenous proteins. $J$ Biol Chem 272, 29127-29136

73. Rabinowitz, J. D., Vrljic, M., Kasson, P. M., Liang, M. N., Busch, R., Boniface, J. J., Davis, M. M., and McConnell, H. M. (1998) Formation of a highly peptidereceptive state of class II MHC. Immunity 9, 699-709

74. Painter, C. A., Cruz, A., Lopez, G. E., Stern, L. J., and Zavala-Ruiz, Z. (2008) Model for the peptide-free conformation of class II MHC proteins. PLoS One $\mathbf{3}$, e2403

75. Rupp, B., Gunther, S., Makhmoor, T., Schlundt, A., Dickhaut, K., Gupta, S., Choudhary, I., Wiesmuller, K. H., Jung, G., Freund, C., Falk, K., Rotzschke, O., and Kuhne, R. (2011) Characterization of structural features controlling the receptiveness of empty class II MHC molecules. PLoS One 6, e18662

76. Stern, L. J., and Wiley, D. C. (1992) The human class II MHC protein HLA-DR1 assembles as empty alpha beta heterodimers in the absence of antigenic peptide. Cell 68, 465-477

77. Kropshofer, H., Arndt, S. O., Moldenhauer, G., Hammerling, G. J., and Vogt, A. B. (1997) HLA-DM acts as a molecular chaperone and rescues empty HLA-DR molecules at lysosomal pH. Immunity 6, 293-302

78. Wilkinson, K. D. (2000) Ubiquitination and deubiquitination: targeting of proteins for degradation by the proteasome. Semin Cell Dev Biol 11, 141-148 
79. Amerik, A. Y., and Hochstrasser, M. (2004) Mechanism and function of deubiquitinating enzymes. Biochimica et Biophysica Acta (BBA) - Molecular Cell Research 1695, 189-207

80. Tholen, S., Biniossek, M. L., Gansz, M., Gomez-Auli, A., Bengsch, F., Noel, A., Kizhakkedathu, J. N., Boerries, M., Busch, H., Reinheckel, T., and Schilling, O. (2013) Deletion of cysteine cathepsins B or L yields differential impacts on murine skin proteome and degradome. Mol Cell Proteomics 12, 611-625

81. Trowsdale, J., and Knight, J. C. (2013) Major Histocompatibility Complex Genomics and Human Disease. Annual review of genomics and human genetics 14, 301-323

82. Dendrou, C. A., Petersen, J., Rossjohn, J., and Fugger, L. (2018) HLA variation and disease. Nat Rev Immunol 18, 325-339

83. Busch, R., Kollnberger, S., and Mellins, E. D. (2019) HLA associations in inflammatory arthritis: emerging mechanisms and clinical implications. Nat Rev Rheumatol 15, 364-381

84. Brodsky, F. M., Parham, P., Barnstable, C. J., Crumpton, M. J., and Bodmer, W. F. (1979) Monoclonal antibodies for analysis of the HLA system. Immunol Rev 47, 3-61

85. Koeffler, H. P., and Golde, D. W. (1978) Acute myelogenous leukemia: a human cell line responsive to colony-stimulating activity. Science 200, 1153-1154

86. Ackerman, A. L., and Cresswell, P. (2003) Regulation of MHC class I transport in human dendritic cells and the dendritic-like cell line KG-1. J Immunol 170, 41784188

87. Berges, C., Naujokat, C., Tinapp, S., Wieczorek, H., Höh, A., Sadeghi, M., Opelz, G., and Daniel, V. (2005) A cell line model for the differentiation of human dendritic cells. Biochemical and Biophysical Research Communications 333, 896907

88. Ning, J., Morgan, D., and Pamphilon, D. (2011) A Rapid Culture Technique Produces Functional Dendritic-Like Cells from Human Acute Myeloid Leukemia Cell Lines. Journal of Biomedicine and Biotechnology 2011, 9

89. Kromer, J. O., Dietmair, S., Jacob, S. S., and Nielsen, L. K. (2011) Quantification of 1-alanyl-1-glutamine in mammalian cell culture broth: Evaluation of different detectors. Anal Biochem 416, 129-131

90. Zaidi, N., Burster, T., Sommandas, V., Herrmann, T., Boehm, B. O., Driessen, C., Voelter, W., and Kalbacher, H. (2007) A novel cell penetrating aspartic protease inhibitor blocks processing and presentation of tetanus toxoid more efficiently than pepstatin A. Biochem Biophys Res Commun 364, 243-249

91. Cardoso, L. S., Araujo, M. I., Goes, A. M., Pacifico, L. G., Oliveira, R. R., and Oliveira, S. C. (2007) Polymyxin B as inhibitor of LPS contamination of Schistosoma mansoni recombinant proteins in human cytokine analysis. Microb Cell Fact 6, 1

92. Hausmann, M., Obermeier, F., Schreiter, K., Spottl, T., Falk, W., Scholmerich, J., Herfarth, H., Saftig, P., and Rogler, G. (2004) Cathepsin D is up-regulated in inflammatory bowel disease macrophages. Clin Exp Immunol 136, 157-167

93. Puizdar, V., Zajc, T., Zerovnik, E., Renko, M., Pieper, U., Eswar, N., Sali, A., Dolenc, I., and Turk, V. (2012) Biochemical characterization and structural 
modeling of human cathepsin E variant 2 in comparison to the wild-type protein. Biol Chem 393, 177-186

94. Shah, N. (2019) Regulation of MHC II protein expression by lysosomal degradation and vitamin $D$. $\mathrm{PhD}$, University of London

95. Lampson, L. A., and Levy, R. (1980) Two populations of Ia-like molecules on a human B cell line. The Journal of Immunology 125, 293

96. Gorga, J. C., Horejsi, V., Johnson, D. R., Raghupathy, R., and Strominger, J. L. (1987) Purification and characterization of class II histocompatibility antigens from a homozygous human B cell line. J Biol Chem 262, 16087-16094

97. Blum, J. S., and Cresswell, P. (1988) Role for intracellular proteases in the processing and transport of class II HLA antigens. Proc Natl Acad Sci U S A 85, 3975-3979

98. Riberdy, J. M., Avva, R. R., Geuze, H. J., and Cresswell, P. (1994) Transport and intracellular distribution of MHC class II molecules and associated invariant chain in normal and antigen-processing mutant cell lines. J Cell Biol 125, 1225-1237

99. Newcomb, J. R., and Cresswell, P. (1993) Structural analysis of proteolytic products of MHC class II-invariant chain complexes generated in vivo. J Immunol 151, 4153-4163

100. Miskiewicz, E. I., and MacPhee, D. J. (2019) Lysis Buffer Choices Are Key Considerations to Ensure Effective Sample Solubilization for Protein Electrophoresis. Methods Mol Biol 1855, 61-72

101. Gruneberg, U., Rich, T., Roucard, C., Marieke van Ham, S., Charron, D., and Trowsdale, J. (1997) Two widely used anti-DR alpha monoclonal antibodies bind to an intracellular C-terminal epitope. Hum Immunol 53, 34-38

102. Brodsky, F. M., Parham, P., and Bodmer, W. F. (1980) Monoclonal antibodies to HLA--DRw determinants. Tissue Antigens 16, 30-48

103. Patil, N. S., Pashine, A., Belmares, M. P., Liu, W., Kaneshiro, B., Rabinowitz, J., McConnell, H., and Mellins, E. D. (2001) Rheumatoid arthritis (RA)-associated HLA-DR alleles form less stable complexes with class II-associated invariant chain peptide than non-RA-associated HLA-DR alleles. J Immunol 167, 71577168

104. De Riva, A., Deery, M. J., McDonald, S., Lund, T., and Busch, R. (2010) Measurement of protein synthesis using heavy water labeling and peptide mass spectrometry: Discrimination between major histocompatibility complex allotypes. Anal Biochem 403, 1-12

105. Athaudaa, S. B., and Takahashia, K. (2002) Cleavage specificities of aspartic proteinases toward oxidized insulin B chain at different $\mathrm{pH}$ values. Protein Pept Lett 9, 289-294

106. Rawlings, N. D., Barrett, A. J., Thomas, P. D., Huang, X., Bateman, A., and Finn, R. D. (2018) The MEROPS database of proteolytic enzymes, their substrates and inhibitors in 2017 and a comparison with peptidases in the PANTHER database. Nucleic Acids Res 46, D624-D632

107. Robinson, J., Barker, D. J., Georgiou, X., Cooper, M. A., Flicek, P., and Marsh, S. G. E. (2020) IPD-IMGT/HLA Database. Nucleic Acids Res 48, D948-D955 
108. McNicholas, S., Potterton, E., Wilson, K. S., and Noble, M. E. (2011) Presenting your structures: the CCP4mg molecular-graphics software. Acta Crystallogr D Biol Crystallogr 67, 386-394

109. Teobald, I., Dunnion, D. J., Whitbread, M., Curnow, S. J., and Browning, M. J. (2008) Phenotypic and functional differentiation of KG-1 into dendritic-like cells. Immunobiology 213, 75-86

110. Holmes, D. T., and Buhr, K. A. (2007) Error propagation in calculated ratios. Clin Biochem 40, 728-734 


\section{Footnotes}

${ }^{1}$ Abbreviations used in this paper: APC, Antigen-presenting cell; CatD/E/G, Cathepsin D/E/G; CD, Cluster of Differentiation; CLIP, Class II-associated invariant chain peptides; HLA, Human leukocyte antigen; Ii, invariant chain; LIP, Leupeptin-induced polypeptide; MARCH-1, Membrane-associated RING-CH 1; MHCII, Major histocompatibility complex class II; MoDC, Monocyte-derived dendritic cell; PepA, Pepstatin A; shRNA, Short hairpin RNA.

${ }^{2}$ The relevant information from our group is in the supplemental data of reference (45). Similar HLA-DR turnover was observed in additional healthy donors (C. Prevosto, A.M. Lipinska, M.J.D., R.B., unpublished data).

${ }^{3}$ A time course of fractional synthesis in Priess cells was previously published (104). Protein fractional synthesis rates in continuously-growing cell cultures under steady-state conditions comprise two additive components: new synthesis need to (i) to maintain protein levels per cell as cells divide, and (ii) to replace proteins lost to turnover. In the Priess labelling experiments (repeated three times with similar results), concurrent measurement of cell growth rates showed that the observed fractional synthesis was entirely explained by cell growth (R.B. and A.D.R., unpublished data). We estimated that the turnover half-life must have been at least 60 hours to explain that there was no detectable difference between the fractional synthesis and cell growth rates.

\footnotetext{
${ }^{4}$ Confirmed by N.S. and R.B. (unpublished data).
} 
Figures and figure legends

A

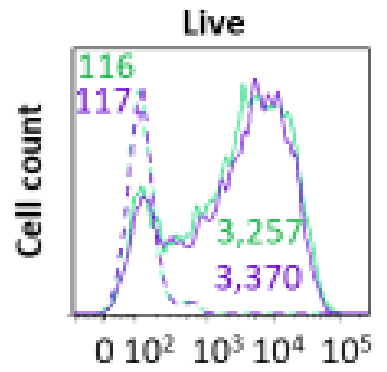

Fixed/permeabilized
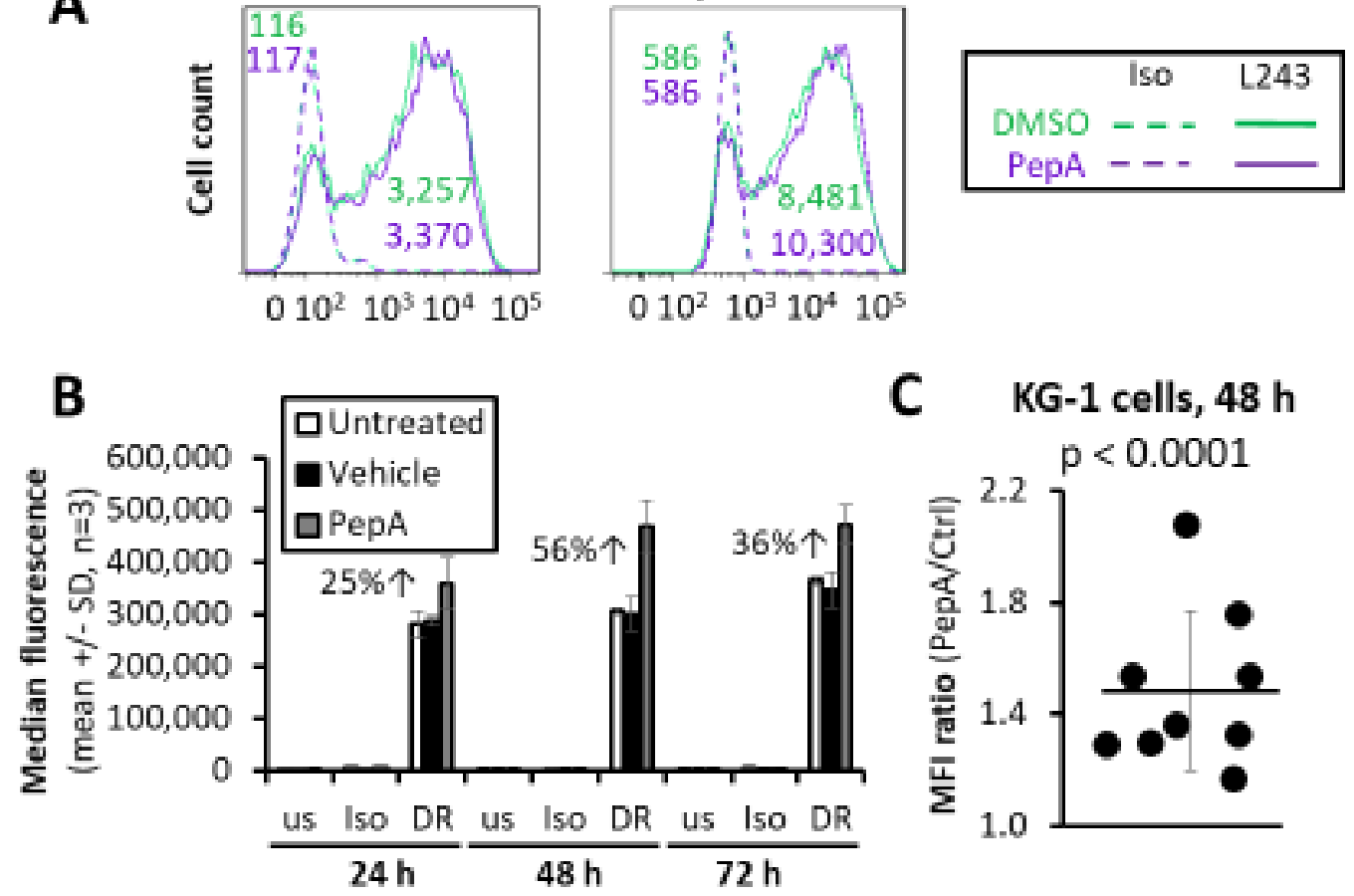

C KG-1 cells, $48 \mathrm{~h}$
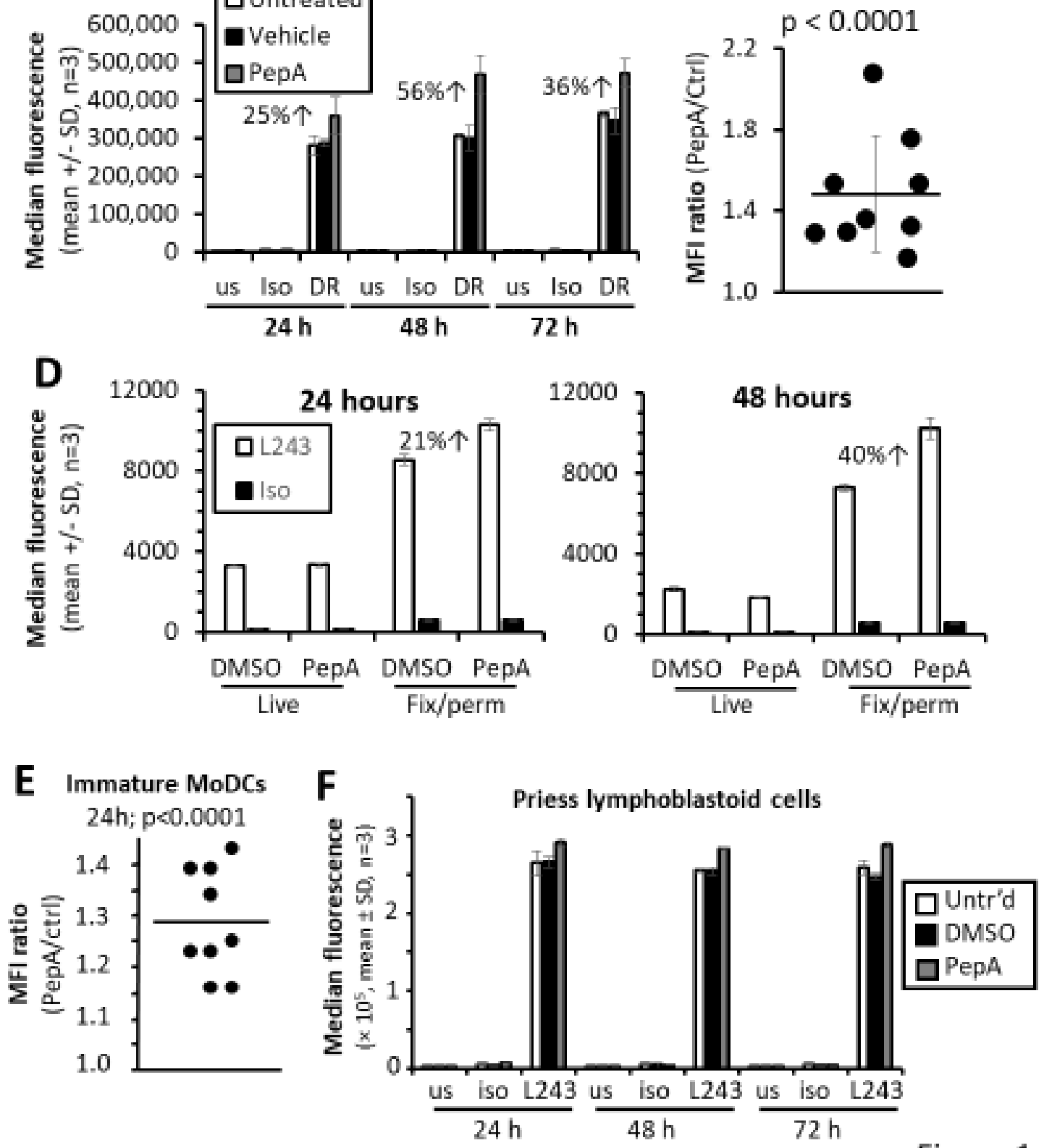

Figure 1 


\section{Fig 1. Rescue of HLA-DR molecules by PepA.}

A, Representative immunofluorescent anti-HLA-DR and isotype control staining profiles of live or fixed, permeabilized KG-1 cells treated with PepA $(20 \mu \mathrm{M})$ or DMSO (vehicle control) for 48 hours. Flow cytometric analysis using FACSCantoII after gating for singlet intact cells. The gating strategy and similar data obtained using an Accuri C6 flow cytometer are shown in Fig. S1, A-C.

$\mathrm{B}$, Median fluorescence intensities (mean $\pm \mathrm{SD}, \mathrm{n}=3$ biological replicats) from a representative experiment as in (A) with daily sampling over 72 hours. Data from untreated and vehicle-treated controls are included, as well as unstained and isotype controls. Analysis using Accuri C6. A 2-way ANOVA of DR staining data indicated significant effects of time in culture $(2 \mathrm{df}, \mathrm{F}=27.5, \mathrm{p}<0.001)$ and treatment $(2 \mathrm{df}, \mathrm{F}=$ $150, \mathrm{p}<0.001)$ and a significant time $\times$ treatment interaction $(4 \mathrm{df}, \mathrm{F}=4.2, \mathrm{p}=0.013)$, consistent with a time-dependent effect of PepA. By Tukey's HSD post-test, the PepA condition was significantly different from untreated and vehicle control $(\mathrm{p}<0.001$ for both). The staining on each day of analysis was done separately, so technical variation in staining may contribute to the time effect.

C, Anti-DR staining ratios (L243-FITC MFI) of PepA-treated cells, divided by vehicle control) after 48 hours of culture, summarizing 9 independent experiments as in (B). $\mathrm{P}$ value was determined by 1 -sample $t$ test against an expectation value of 1.0 (representing no PepA effect).

D, HLA-DR or isotype control staining of KG-1 cells after $24 \mathrm{~h}$ (left) or $48 \mathrm{~h}$ (right) of culture with PepA or DMSO control, comparing staining of live and fixed, permeabilized cells. At both time points, a 2-way ANOVA of DR staining data showed significant 
effects $(\mathrm{p}<0.0001 \mathrm{each})$ of inhibitor treatment, of fixation and permeabilization, and of the interaction between these two factors.

E, Immature MoDCs from healthy donors were differentiated for 7 days, then cultured with $20 \mu \mathrm{M}$ PepA or vehicle control for a further 24 hours before analysis similar to (C), except that single measurements were performed (see Fig. S3). Shown are anti-DR staining ratios (L243-FITC MFI in PepA-treated cells divided by vehicle controls) from 9 independent experiments with MoDCs from 5 donors.

F, Experiment as in Fig. 1B, but using the lymphoblastoid cell line, Priess. The small treatment effect in this attempt $(\approx 10 \%$ increase) was statistically significant $(2 \mathrm{df}, \mathrm{F}=$ $30.8, \mathrm{p}<0.001)$, but there was no statistical evidence for accumulation over time ( $4 \mathrm{df}, \mathrm{p}$ $=0.952$ for interaction), and the increased anti-DR staining in PepA-treated cells was not reproduced consistently in 4 independent repeats. 

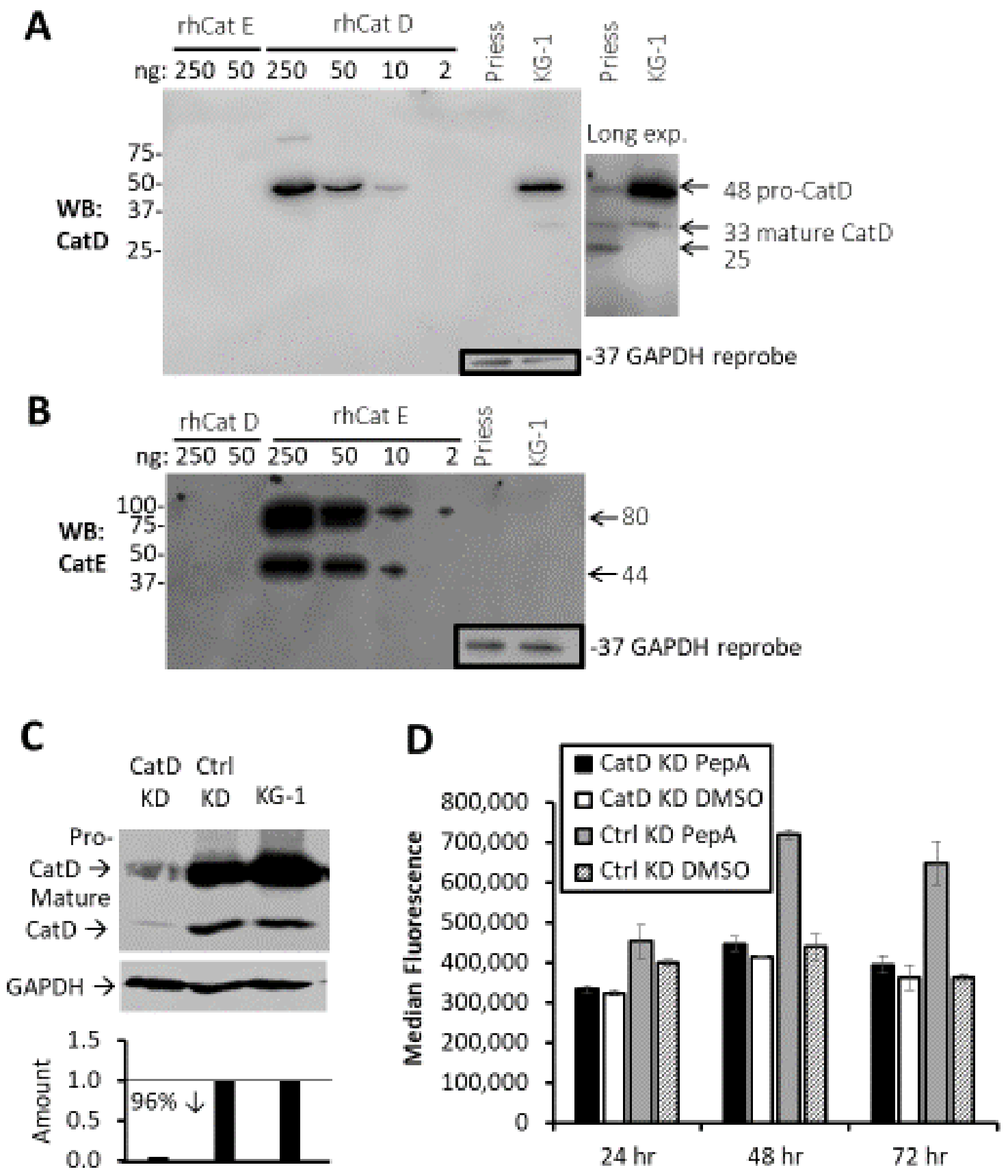

Figure 2 


\section{Fig. 2. Role of CatD in HLA-DR degradation in KG-1 cells.}

A and B, Western blot analysis of KG-1 and Priess extracts using anti-CatD (A) and antiCatE (B) antibodies. Titrated amounts of recombinant human CatD and CatE are included as specificity controls and semiquantitative standards. Insets show GAPDH loading controls (vertically displaced) for the Priess and KG-1 extracts after re-probing. C, shRNA-mediated knockdown of CatD protein expression, shown by anti-CatD Western blot of KG-1 cells lentivirally transduced with CatD shRNA knockdown construct (KD), compared to empty-vector control (top). After re-probing for GAPDH as a loading control (middle), band intensities were quantified, showing 96\% knockdown (bottom).

D, PepA effect on HLA-DR expression in CatD-knockdown and empty vector controltransduced KG-1 cells, analysed over 3 days. Means \pm SDs of triplicates are shown. Analysis by 2-way ANOVA for PepA and knockdown effects at each time point. In the control knockdown cells, the PepA effect (1 df) was statistically significant at each time point $(24$ h: $F=81.2, p=0.001 ; 48$ h: $F=201, p<0.001 ; 72$ h: $F=81.0, p=0.001)$. In CatD knockdown cells, the effect of PepA was not statistically significant at any time point (24 h: $F=9.6, p=0.086 ; 48 h: F=5.7, p=0.05 ; 72 h: F=0.1, p=0.221)$. 
A

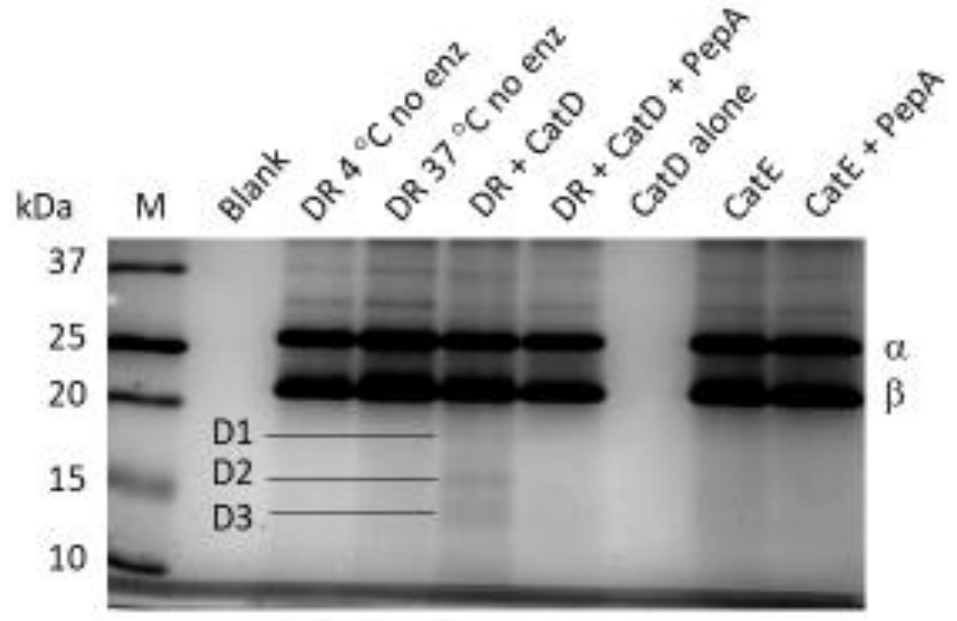

B

$\mathrm{kDa}$

$27 \alpha$
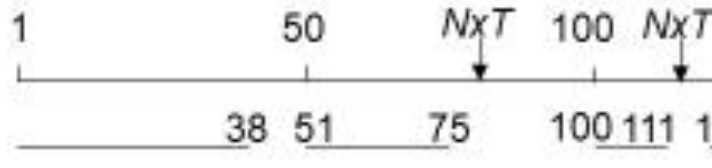

150

192

18 D1

16 D2

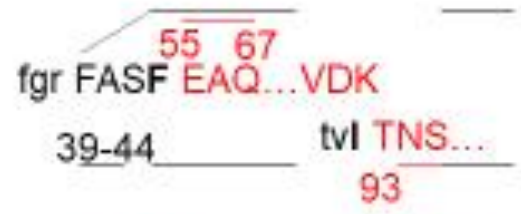

14 D3

45-51 wr LEEFGRF
VEH, PLL/K/H

$165-175 / 6 / 7$

C

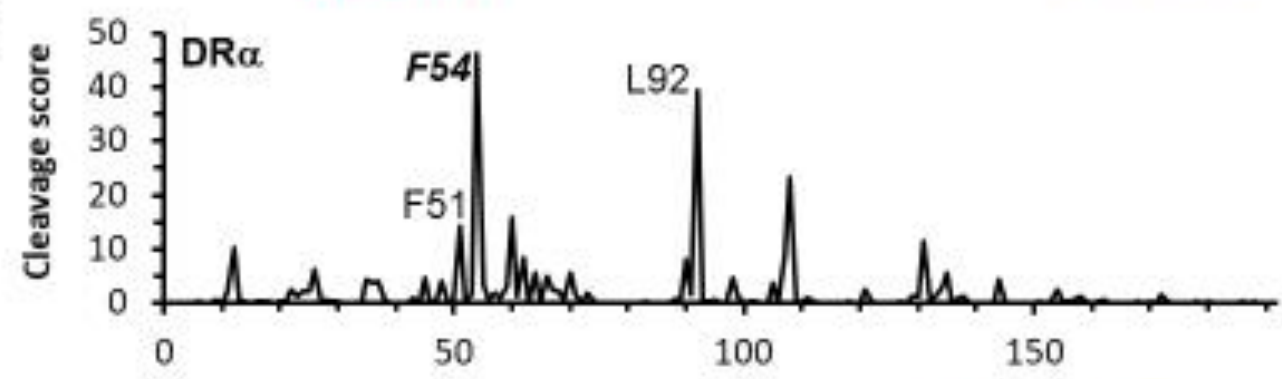

D

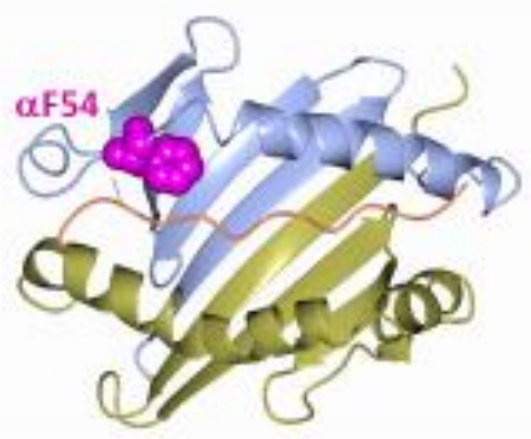

Residue no.

Figure 3 


\section{Fig. 3. Cleavage of HLA-DR by CatD in vitro.}

A, Analysis of CatD digests. Purified soluble recombinant HLA-DR0402 protein was

digested for 16 hours with or without $\mathrm{CatD}$ at $37{ }^{\circ} \mathrm{C}$ and $\mathrm{pH} 4.5$, as shown, or kept at $4{ }^{\circ} \mathrm{C}$.

As a further negative control, CatD was blocked with excess PepA before digestion.

Digests were resolved by SDS-PAGE, and the intact $\alpha$ and $\beta$ chains, as well as the indicated fragments, were excised for tandem mass spectrometry.

$\mathrm{B}$, Schematic map of fragments (horizontal lines) found in the intact $\alpha$ chain and the CatD fragments D1/2/3 shown in (A). Black lines and numbers show the mapping of tryptic fragments to the expected amino acid sequence. Red lines and uppercase red text and numbers show additional peptides, which were absent from the intact $\alpha$ chain and compatible with CatD cleavage (cf. (C)). Purple dashed lines, text and numbers show peptides in the D3 fragment that were absent from the intact chain but were not explained by CatD cleavage. For analysis of $\beta$-chain-derived sequences, see Fig. S6A. The sequence alignments for both chains are shown in Table $\mathbf{S 1 .}$

C, Predicted CatD cleavage preferences in the HLA-DR $\alpha$ chain. The Y axis indicates relative predicted cleavage probability (Experimental Procedures, Tables S2-S4 and supporting text); the $\mathrm{Y}$ axis indicates primary sequence position, aligned with the map in (B). The novel observed fragments are compatible with peak cleavage probabilities. D, Views of the DR0101-CLIP crystal structure (PDB: 3QXA) showing the location of the residues in the $\mathrm{P} 1$ position relative to the observed CatD cleavage sites. Polypeptide main chains are color-coded blue (DR $\alpha)$, gold (DR $\beta)$, pink (CLIP). Space-filling models of side chains are shown in magenta for the initial cleavage site at $\alpha \mathrm{F} 54$, and in green for the secondary cleavage sites $(\alpha \mathrm{L} 92, \alpha \mathrm{F} 51)$. Left, top view of the peptide-binding groove 

available under aCC-BY-NC-ND 4.0 International license.

showing only the initial cleavage site. The main-chain nitrogen of $\alpha \mathrm{F} 54$ hydrogen-bonds with CLIP (dashed line). Right, side view of the entire structure (with CLIP N terminus pointing towards the reader), with the locations of all cleavage sites shown. 
A

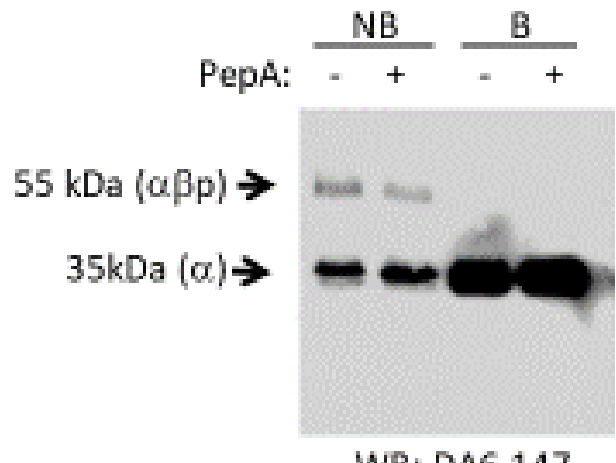

$\frac{N B}{+-} \frac{B}{+-}$

WB: DA6.147

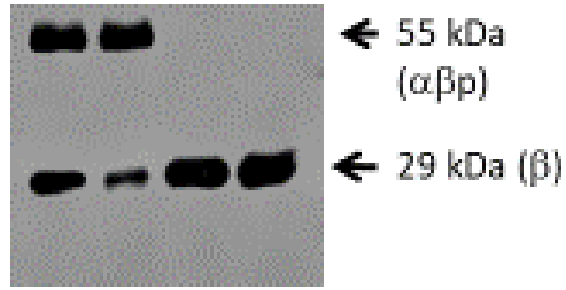

WB: DA2
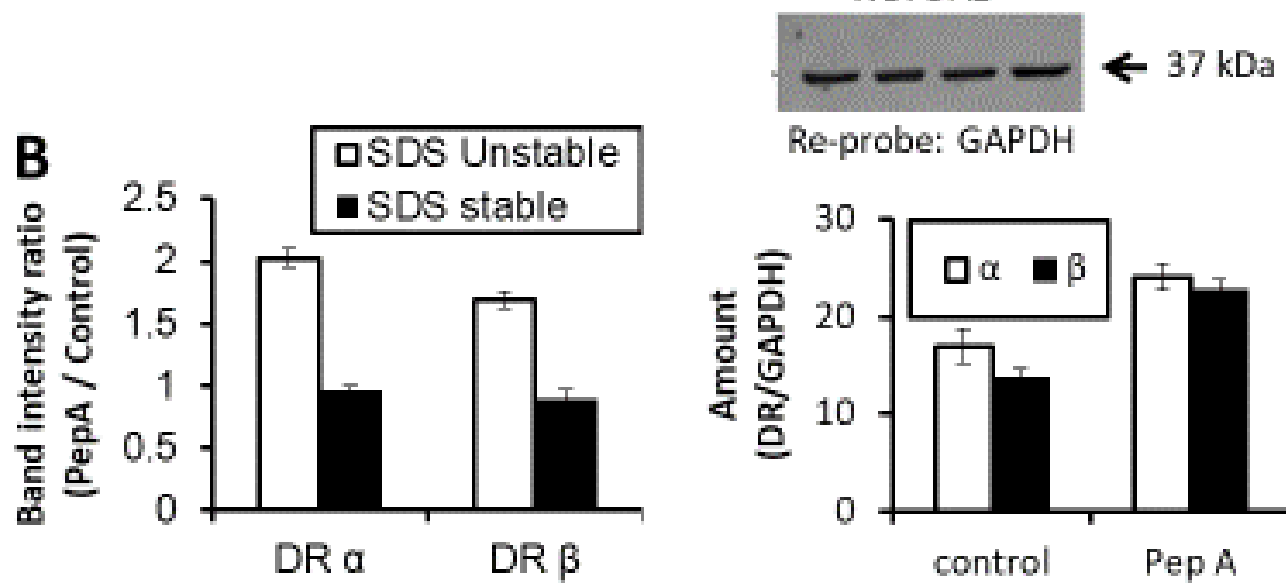

Re-probe: GAPDH

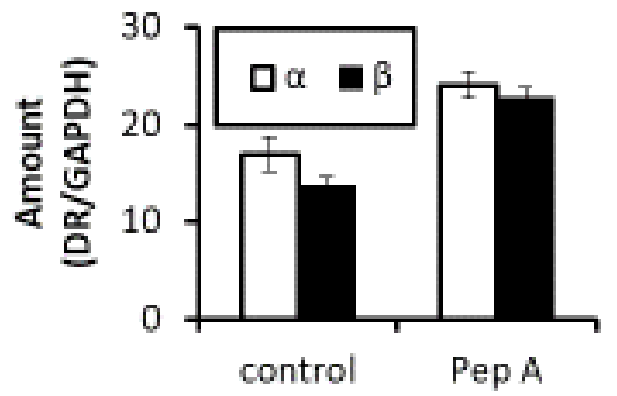

C

D
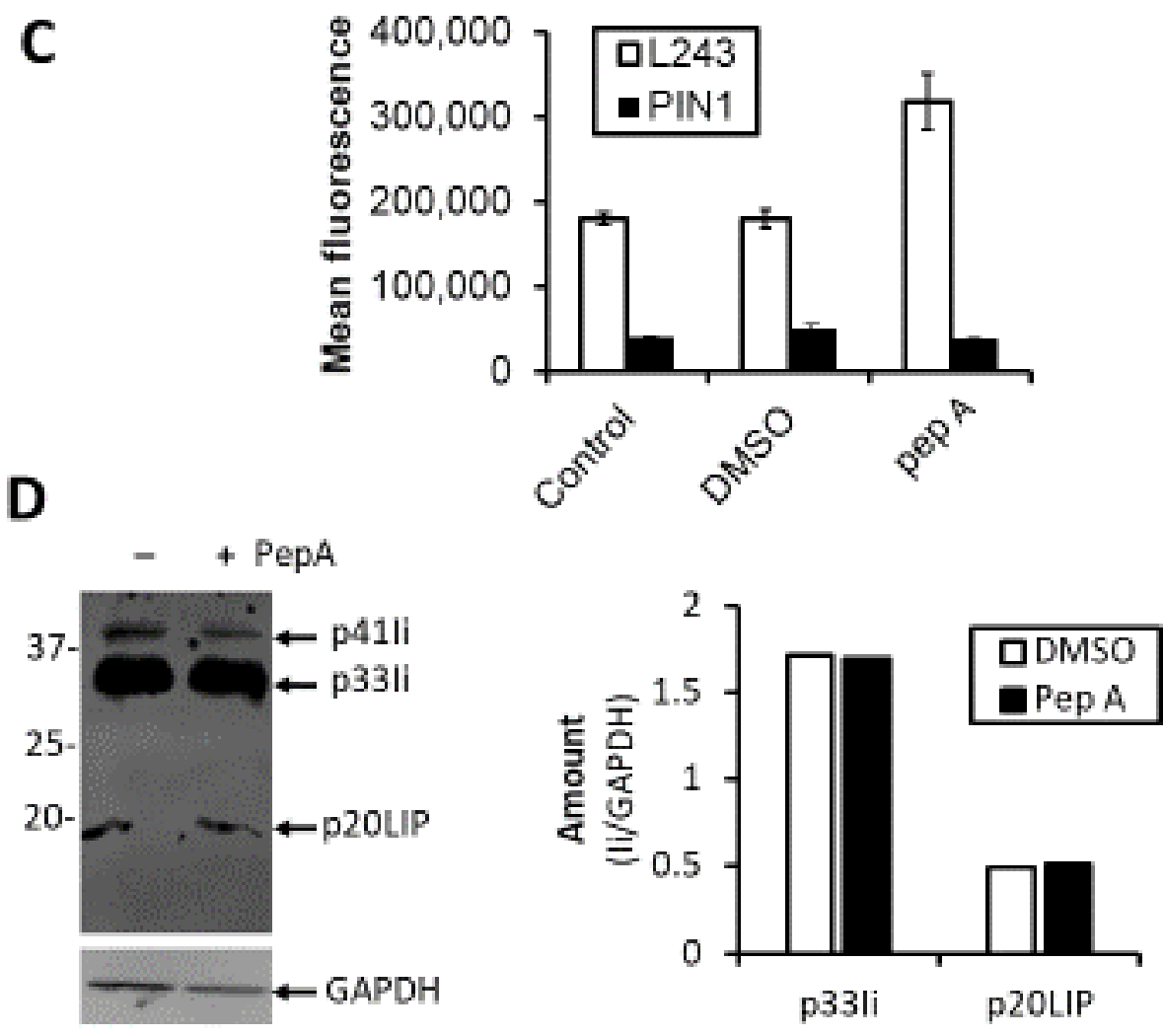

Figure 4 


\section{Fig. 4. Characterisation of the forms of HLA-DR rescued by PepA.}

A, SDS stability. KG-1 cells were grown for 2 days in the presence of $20 \mu \mathrm{M}$ PepA or vehicle control (DMSO) as indicated. Total protein-matched, non-boiled (NB) or boiled (B) cell extracts were resolved by $12 \%$ nonreducing SDS-PAGE, and Western blots probed with antibodies to HLA-DR $\alpha$ (left) and $\beta$ chains (right). The blot for the $\beta$-chain was re-probed for GAPDH (bottom right).

B, Quantification of band intensities in A. Left, band intensities representing monomers and SDS $\alpha \beta /$ peptide complexes in non-boiled samples from A were quantified by using LiCor imager, and the effects of PepA shown as a bar graph. Right, GAPDH-normalised band intensities in boiled samples were used to quantify rescue of total DR molecules. Bar graphs show mean \pm SD of two independent experiments.

C, Flow cytometric analysis for Ii. KG-1 cells were treated with or without PepA as in B, fixed and permeabilized, and analysed by flow cytometry after staining with a mAb specific for the cytoplasmic tail of Ii (PIN.1) or, as a positive control, with mAb against mature, Ii-non-associated DR (L243). An example of staining with specificity controls is shown in Fig. S1D. At 48 h, the anti-DR staining differed significantly between culture conditions (1-way ANOVA, $2 \mathrm{df}, \mathrm{F}=18.2, \mathrm{p}<0.001)$, but the anti-Ii staining did not (2 df, $\mathrm{F}=1.4, \mathrm{p}=0.28)$.

D, Western blot analysis for Ii. Extracts from KG-1 cells treated for 48 hours with or without PepA were resolved by SDS-Page and Western blots probed with anti-Ii mAb PIN.1 (left). The intensities of the p33Ii and p20LIP bands were quantified (right). The experiment was performed only once, but the results conformed to those in Fig. 4D and Fig. S2A. 
A

\begin{tabular}{|c|c|c|c|c|c|c|c|}
\hline Property & DR/li & $\begin{array}{c}\text { DR/ } \\
\text { p20 } \\
\text { LIP }\end{array}$ & $\begin{array}{c}\text { DR/ } \\
\text { CLIP }\end{array}$ & $\begin{array}{c}\text { DR/ } \\
\text { pep }\end{array}$ & Ub-DR & $\begin{array}{c}\text { "Empty" } \\
\text { DR }\end{array}$ & Observed \\
\hline $\begin{array}{c}\text { PIN.1 } \\
\text { reactive }\end{array}$ & + & + & - & - & - & - & - \\
\hline $\begin{array}{c}\text { L243 } \\
\text { reactive }\end{array}$ & low & High & High & High & High & High & + \\
\hline $\begin{array}{c}\text { Cer-CLIP } \\
\text { reactive }\end{array}$ & - & - & + & - & - & - & Not det'd \\
\hline $\begin{array}{c}\beta \text { chain } \\
\text { MW }\end{array}$ & $29 \mathrm{kD}$ & $29 \mathrm{k}$ & $29 \mathrm{kDa}$ & $29 \mathrm{kDa}$ & $\begin{array}{c}>37 \\
\mathrm{kDa}\end{array}$ & $29 \mathrm{kDa}$ & $29 \mathrm{kDa}$ \\
\hline SDS stable & - & - & - & + & - & - & - \\
\hline
\end{tabular}

B

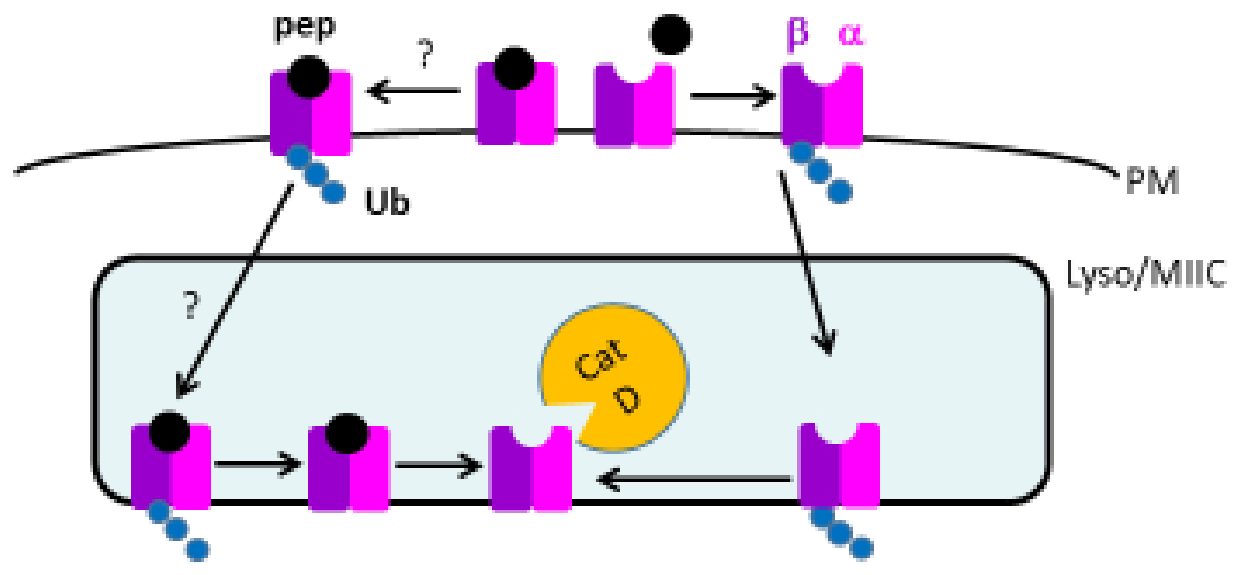

C

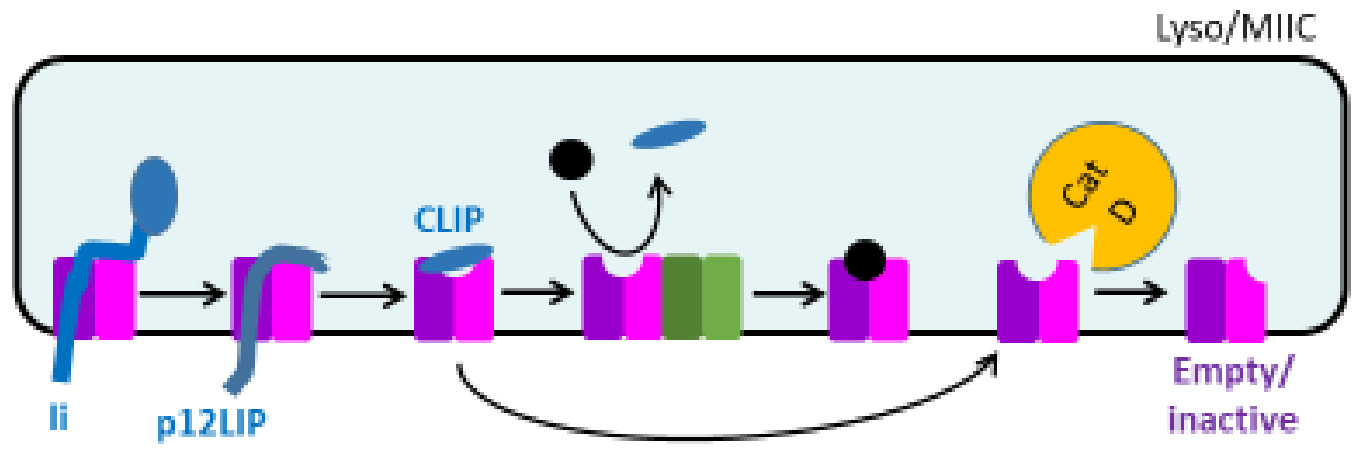

Figure 5 
Fig. 5. Working model of CatD-mediated HLA-DR protein turnover. See text for details and citations.

A, Table comparing the biochemical characteristics of PepA-rescued DR molecules (from Fig. 4) with various stages in DR maturation.

$\mathrm{B}$, Postulated role of CatD in the initial proteolytic attack on empty MHCII molecules following $\beta$-chain ubiquitylation, internalization to lysosomes, de-ubiquitylation, and loss of bound peptide. Selective attack on empty (or poorly-loaded) MHCII molecules may occur because hydrogen-bonding with stably-bound peptide prevents access of CatD to the scissile bond at $\alpha$ F54 (cf. Fig. 3D); in addition, it is conceivable that empty/poorlyloaded DR may be preferentially ubiquitylated and internalized, as compared to DR molecules stably loaded with peptide (indicated by “??”).

C, Molecular interactions with Ii, DM and peptide along the classical MHCII maturation and peptide loading pathway would prevent initial CatD attack on the scissile bond at $\alpha$ F54. Conformational changes of empty DR following peptide release may also influence CatD susceptibility.

[end of main paper] 